ALAN B. KRUEGER

Princeton University

JUDD CRAMER

Princeton University

DAVID CHO

Princeton University

\title{
Are the Long-Term Unemployed on the Margins of the Labor Market?
}

\begin{abstract}
Long-term transition rates calculated from the Current Population Survey, the Survey of Income and Program Participation, and Rutgers University's Work Trends Survey indicate that the long-term unemployed have a 20 to 40 percent lower probability of being employed 1 to 2 years in the future than do the short-term unemployed. In comparison with the short-term unemployed, for the long-term unemployed the job finding rate is less sensitive to the state of the business cycle, but their labor force withdrawal rate is more procyclical. A calibration exercise finds that the tendency of the labor force withdrawal rate of the long-term unemployed to decline in a recession and then rise in a recovery plays an important role in the well-documented loop around the Beveridge curve. Overall, the results suggest that the longer workers are unemployed, the less attached they become to the labor market.
\end{abstract}

\footnotetext{
A number of observers have noted that in recent years conventional Phillips curve and Beveridge curve models have predicted greater price deflation, greater real wage declines, and fewer vacancies than actually occurred as a result of the high rate of unemployment experienced during the Great Recession and its aftermath. Several economists have provided possible explanations for the missed predictions of the Phillips curve, based on anchoring of inflation expectations (Bernanke 2007 and 2010) or changes in the distribution of price increases and interactions in the Phillips curve (Ball and Mazumder 2011). Others have shown that price and wage Phillips curves are stable if the short-term unemployment rate is used instead of the total unemployment rate (Stock 2011, Gordon 2013, Watson 2014,
} 
and U.S. Council of Economic Advisors 2014), while others have shown that the Beveridge curve is stable if the short-term unemployment rate is used instead of the total unemployment rate (Ghayad and Dickens 2012).

This paper explores the extent to which the long-term unemployed, whose share of overall unemployment rose to an unprecedented level after the Great Recession, are on the margins of the labor force and are, therefore, possibly exerting little pressure on wage growth or inflation and slowing the process of matching unemployed workers to job vacancies. The hypothesis we seek to test is that the longer workers are unemployed the less they become tied to the job market, either because, on the supply side, they grow discouraged and search for a job less intensively (Krueger and Mueller 2011), or because, on the demand side, employers discriminate against them, based on the expectation (whether rational or irrational) that there is a productivity-related reason that accounts for their long jobless spell (Kroft and others 2014; and Ghayad 2013). Either of these explanations would imply that the long-term unemployed are on the margins of the labor market. Moreover, the demand-side and supply-side effects of longterm unemployment can be viewed as complementary explanations that reinforce one another rather than competing explanations, because statistical discrimination against the long-term unemployed could lead to discouragement, and the skill erosion that accompanies long-term unemployment could induce employers to discriminate against the long-term unemployed.

We assemble varied evidence to assess the hypothesis that the longterm unemployed are on the margins of the labor market. To preview our main findings, we tentatively conclude that the long-term unemployed are less connected to the economy than the short-term unemployed, and that many eventually withdraw from the labor force. The chance of holding a full-time, steady job for those who became unemployed in the 2008-12 period was 19 percent at the start of their unemployment spell, 11 percent after 7 months without working, and only 6 percent after 2 years without working. ${ }^{1}$ Nearly half of those who were jobless for seven months or longer had withdrawn from the labor force within 15 months of becoming unemployed in 2012. Even at times when-or in regions where-the economy is relatively strong, the long-term unemployed face long odds of returning to steady, full-time employment. We also find that the long-term unemployed are about 60 percent as effective at matching to job openings as are the short-term unemployed. Furthermore, job finding rates are more

1. Steady, full-time employment in this context means that someone who was unemployed in month $t$ was employed full-time for 4 consecutive months starting in month $t+12$. 
sensitive to the state of the business cycle for the short-term unemployed than the long-term unemployed, suggesting that the long-term unemployed are more insulated from macroeconomic developments.

This paper is organized as follows. Section I provides a detailed profile of the long-term unemployed, and examines how their composition has varied over time. While some notable industries (such as construction) and demographic groups (such as African Americans) are overrepresented among the long-term unemployed, the long-term unemployed are ubiquitous and spread throughout all corners of the economy. We find only modest changes in the composition of the unemployed over the business cycle, with those who are unemployed during recessions tending to have more highly rewarded characteristics than those who are unemployed during expansions.

Sections II and III examine the rates at which unemployed workers find employment or exit the labor force, by duration of unemployment. Using matched Current Population Survey (CPS) data we examine transition rates both over a month and over a year or more. Longer durations of unemployment are associated with lower rates of transition into employment, although there is debate as to whether the observed duration dependence is a result of heterogeneity among workers or changes in the employability of job seekers that take place during long jobless spells (Heckman and Singer 1984, Chan and Stevens 2001). From 2008 to 2012, 35.9 percent of those who were long-term unemployed (that is, unemployed for 7 months or longer) in a given month in the CPS were employed 15 months later, and 10.8 percent were employed steadily in a full-time position; the comparable figures for the short-term unemployed were 49.5 percent and 14.4 percent, respectively.

The long-term unemployed normally have a higher rate of labor force withdrawal than the short-term unemployed, although we document that following a recession the labor force withdrawal rates for all duration groups tend to collapse to a common, lower level. Nearly a fifth of the cyclical movement in the labor force attachment of the long-term unemployed appears to be related to shifts in the observed characteristics of the unemployed over the business cycle. The cyclical behavior of labor force withdrawal is also consistent with the expiration of extended unemployment insurance benefits leading the long-term unemployed to exit the labor force. The countercyclical pattern of labor force participation of the long-term unemployed suggests that a critical channel for the future path of long-term unemployment in the United States involves the evolution of labor force withdrawal rates by duration of unemployment. 
Transition rates in the CPS have well-known measurement problems, because workers who are misclassified in one period and then correctly categorized in the following month will falsely appear as if they changed labor force status across these periods, even though they had not changed labor market status. Another limitation of the CPS data for our analysis is that the survey does not follow individuals who move to new locations. Therefore, we supplement the analysis with two additional data sets in sections IV and V: the Survey of Income and Program Participation (SIPP) and Rutgers University's Hildreth Center's Work Trends Survey, a panel survey of workers who were unemployed between September 2008 and August 2009. ${ }^{2}$ Despite their design differences, it is reassuring that the SIPP and Work Trends Survey yield qualitatively similar results to the CPS. Even across varying intervals, definitions of short- and long-term unemployed, and job definitions, all three yield job finding rates that are about 20 to 40 percent lower for the long-term unemployed than for the short-term unemployed.

To further explore the effect of a stronger economy on the prospects of the unemployed, section VI compares trends in long-term and short-term unemployment in different regions of the United States. Our analysis indicates that long-term unemployment has remained elevated even in states where the total unemployment rate has fallen below its historical average. In addition, the long-term unemployed appear to be following a similar path in terms of job finding rates and labor force exit rates in both low-unemployment and high-unemployment states. By contrast, the short-term unemployed have exhibited higher job finding rates in low-unemployment states.

In section VII we explore whether the Beveridge curve can be caused to loop around a stable path following a sharp downturn by a process of labor force withdrawal rates collapsing and then gradually returning to their historical norm - with higher exit rates for the long-term unemployed - as well as a lower match efficiency for the long-term unemployed. Specifically, we extend the calibration-type model of Kory Kroft and others (2014) to allow for varying labor force exit rates and differential match efficiency for the long-term unemployed to project the path of the Beveridge curve under a stable matching function. ${ }^{3}$ The results suggest that from 2002 to 2007 the

2. The CPS captures all ongoing spells of unemployment at a point in time, whereas the SIPP and Work Trends Survey capture new spells of unemployment occurring over a specified period of time, but under reasonable assumptions all three surveys should yield representative estimates of job finding rates by duration of unemployment.

3. To be fair, Kroft and others (2014) allow for differential match efficiency of the longterm unemployed through a multiplicative term, but they do not allow for a differential effect in the "meeting" function. 
long-term unemployed were about 60 percent as efficient in job matching as the short-term unemployed. Using the matching function estimated for the 2002-07 period, the calibrated model does a reasonably good job of capturing the rise in unemployment and the outward shift of the Beveridge curve in the 2008-13 period as well as the rise in the share of unemployed workers who are long-term unemployed.

Using the calibrated model to conduct a counterfactual simulation, we find that both the lower match efficiency of the long-term unemployed and their countercyclical pattern of labor force withdrawal have played an important role in the rising unemployment rate and the shift of the Beveridge curve since the Great Recession. Future projections predict a gradual return to the original Beveridge curve as the share of long-term unemployment declines due to labor force exits or transitions to employment. The gradual withdrawal from the labor force of many of the longterm unemployed is a potential source of hysteresis effects (Blanchard and Summers 1987 and DeLong and Summers 2012).

Section VIII concludes the paper by briefly considering some of the policy implications of the hypothesis that many of the long-term unemployed are on the margins of the labor market. Perhaps most importantly, our findings suggest that a concerted effort will be required to raise the employment prospects of the long-term unemployed, especially since they are likely to withdraw from the job market at an increasing rate if they continue to follow the same path as in the previous recovery.

\section{Profile of the Long-Term and Short-Term Unemployed}

For background, this section provides a detailed portrait of the longterm unemployed in comparison to employed workers and short-term unemployed workers. We begin by reviewing trends in the incidence of long-term unemployment, then summarize characteristics of the long-term unemployed, and then examine how a summary measure of the composition of the long-term unemployed (based on earnings prospects) has varied over time.

Figure 1 displays duration-specific unemployment rates in the United States based on published seasonally adjusted monthly data from the Bureau of Labor Statistics (BLS) from January 1948 through May 2014. The dark line indicates the long-term unemployment rate (defined as the number unemployed for 27 weeks or longer divided by the labor force), whereas the dotted line is the similarly defined unemployment rate for those unemployed for 14 weeks or less, and the dashed line is the rate for 
Figure 1. Unemployment Rates by Duration, 1948-2014

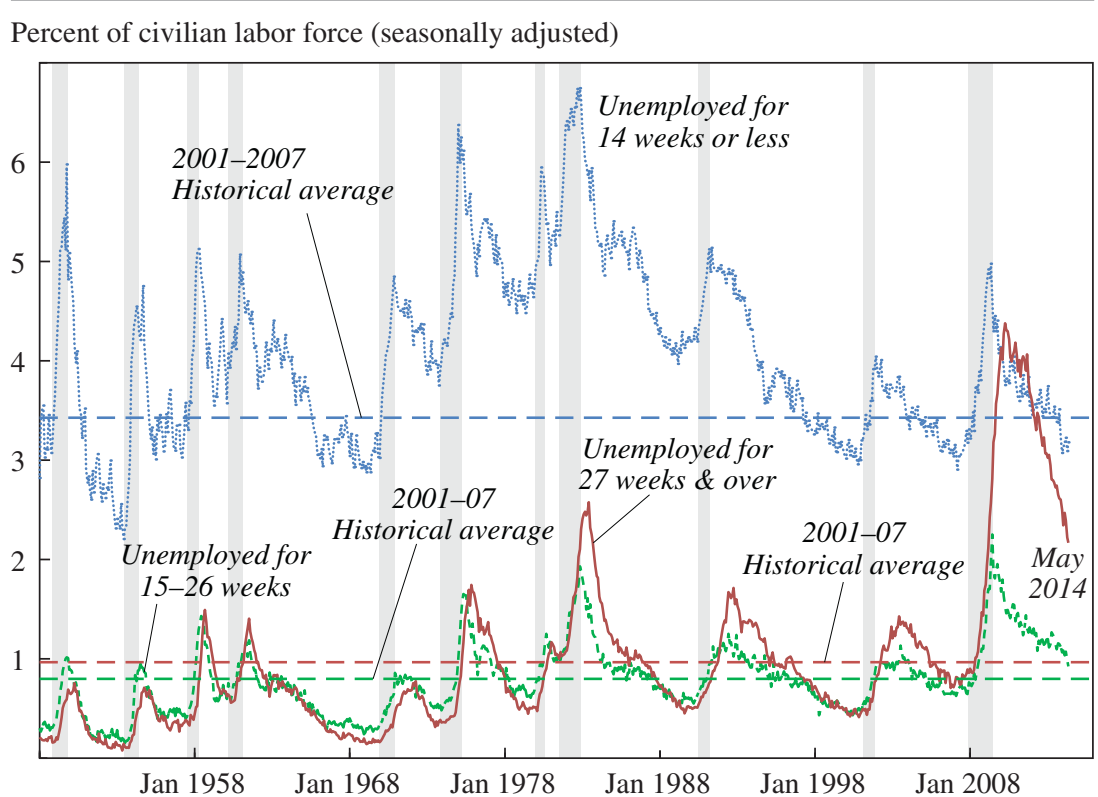

Source: Bureau of Labor Statistics (Current Population Survey); National Bureau of Economic Research. Note: Shading denotes recession.

the intermediate group unemployed for 15 to 26 weeks. Notice that the long-term unemployment rate, which tends to rise during periods of recession and peak shortly afterwards, jumped to record heights during the Great Recession and peaked in early 2010 before starting to decline. Despite declining over the last 4 years, in 2013 it exceeded its previous annual peak before the Great Recession, reached in the aftermath of the deep 1981-82 recession, and was well above its average in the last recovery. The two measures of short-term unemployment, however, have returned to close to the average rates they displayed during the last recovery. Thus, as an accounting matter, unemployment remains elevated because of the large number of people who have been unemployed for more than half a year.

For most of the six decades prior to the Great Recession, the share of the unemployed in the United States who were out of work for more than half a year oscillated between 10 and 20 percent during recoveries and recessions. ${ }^{4}$ The share of the unemployed who were long-term job seekers

4. See Abraham and Shimer (2002) for a careful analysis of why the duration of unemployment in the U.S. rose relative to the unemployment rate in the 1980s and 1990s. 
averaged over 40 percent in 2010, 2011, and 2012-reaching as high as 45 percent-and as of this writing stood at 35 percent. The long-term unemployed, therefore, exert a more significant effect on unemployment dynamics today than they have in the past.

Table 1 reports the distribution of both employees and people on shortterm or long-term unemployment spells along several dimensions for the United States, using data from the 2013 CPS. For example, the table indicates that 34 percent of employed individuals are ages 16 to 34, 32 percent are ages 35 to 49 , and 33 percent are ages 50 and older. Compared to their share of employment, young people are notably overrepresented among the short-term unemployed, while the middle-aged group is underrepresented. Compared to their share of the short-term unemployed, the oldest group is overrepresented among the long-term unemployed, although their share of the long-term unemployed almost matches their share of employment.

If the unemployed as a whole are compared to the employed, notably larger shares of the unemployed are younger, unmarried, and less well educated. For example, although about one-third of employed workers have earned a bachelor's degree, less than 20 percent of the unemployed have done so. By contrast, nearly 20 percent of the unemployed lack a high school diploma, which is twice the rate for the employed. African Americans and Hispanics are also overrepresented among the unemployed. Not surprisingly, given the housing bubble earlier in the 2000s, a higher proportion of the unemployed previously worked in the construction industry than the share of workers currently employed as construction workers; nonetheless, only 11 percent of all unemployed workers were previously in the construction industry.

When compared to the short-term unemployed, a larger proportion of the long-term unemployed are over age 50 and are African American. Workers age 50 and over make up 30 percent of the long-term unemployed but just 20 percent of the short-term unemployed. African Americans constitute 23 percent of the long-term unemployed, compared with just 11 percent of the employed population and 17 percent of the short-term unemployed.

Along many other dimensions, however, the long-term unemployed appear broadly similar to the short-term unemployed. The educational achievement of the two groups is comparable, and both the industry distribution and occupational distribution are similar. The long-term unemployed are almost as likely to be unmarried as the short-term unemployed. And differences across regions and between urban and rural areas (not shown in table 1) are also small. 
Table 1. Profile of the Employed, Short-Term Unemployed, and Long-Term Unemployed, 2013

\begin{tabular}{|c|c|c|c|}
\hline & $\begin{array}{l}\text { Percent of } \\
\text { employed }\end{array}$ & $\begin{array}{c}\text { Percent of } \\
\text { short-term } \\
\text { unemployed } \\
(<14 \text { Weeks })\end{array}$ & $\begin{array}{c}\text { Percent of } \\
\text { long-term } \\
\text { unemployed } \\
\text { (>26 Weeks) }\end{array}$ \\
\hline \multicolumn{4}{|l|}{ Gender } \\
\hline Male & 53 & 55 & 56 \\
\hline Female & 47 & 45 & 44 \\
\hline \multicolumn{4}{|l|}{ Age } \\
\hline $16-34$ & 34 & 57 & 42 \\
\hline $35-49$ & 32 & 23 & 28 \\
\hline $50+$ & 33 & 20 & 30 \\
\hline \multicolumn{4}{|l|}{ Marital status } \\
\hline Married & 56 & 33 & 34 \\
\hline Widowed/divorced/separated & 15 & 14 & 19 \\
\hline Never married & 29 & 53 & 47 \\
\hline \multicolumn{4}{|l|}{ Race } \\
\hline White, Non-Hispanic & 66 & 55 & 51 \\
\hline African American & 11 & 17 & 23 \\
\hline Hispanic & 16 & 21 & 18 \\
\hline Asian/Pacific Islanders & 6 & 4 & 5 \\
\hline Other & 2 & 3 & 3 \\
\hline \multicolumn{4}{|l|}{ Education } \\
\hline Less than high school & 9 & 22 & 18 \\
\hline High school & 27 & 33 & 36 \\
\hline Some college & 19 & 21 & 20 \\
\hline Associate's degree & 11 & 8 & 9 \\
\hline Bachelor's degree or higher & 35 & 17 & 19 \\
\hline \multicolumn{4}{|l|}{ Industry ${ }^{\mathrm{a}}$} \\
\hline Construction & 6 & 12 & 10 \\
\hline Manufacturing & 10 & 9 & 11 \\
\hline Wholesale and retail trade & 14 & 14 & 16 \\
\hline Finance and real estate & 7 & 4 & 5 \\
\hline Professional and business services & 12 & 14 & 14 \\
\hline Education and health care & 23 & 15 & 15 \\
\hline Leisure and hospitality & 9 & 16 & 12 \\
\hline All other & 19 & 16 & 16 \\
\hline \multicolumn{4}{|l|}{ Occupation $^{\mathrm{a}}$} \\
\hline Professional and technical & 22 & 12 & 11 \\
\hline Managerial and financial & 16 & 7 & 9 \\
\hline Administrative & 12 & 12 & 15 \\
\hline Sales and service & 32 & 40 & 38 \\
\hline Blue collar & 17 & 29 & 27 \\
\hline
\end{tabular}

Source: Authors' calculations from the Current Population Survey.

a. Industry and occupation refer to the previous job held by the unemployed, for those who held jobs. 
About two-thirds of both short-term and long-term unemployed workers last held jobs in two occupational categories, blue-collar jobs and sales and service jobs, whereas those occupations comprised just under half of all employed workers.

The similar industrial, occupational, and educational composition of short-term and long-term unemployed workers suggests that differential mismatch between workers and the types of jobs available does not account for much of the occurrence of long-term unemployment. From the limited information available in the CPS, the long-term unemployed seem to be qualified for about the same mix of jobs as the short-term unemployed. Thus, if there is a structural problem currently confronting the long-term unemployed that pushes them to the margins of the labor market, it presumably has come about because their skills, motivation to find a job, or self-esteem eroded during their long stretch of unemployment, or because employers treat the long-term unemployed differently, rather than because of different backgrounds possessed by the long-term unemployed at the start of their spells of unemployment. We return to this issue below.

\section{I.A. Composition of the Unemployed over Time}

Table 1 summarizes the characteristics of the unemployed in 2013, but there has been a large increase in the number of long-term unemployed and potential compositional shifts since the Great Recession. To create a summary measure of the characteristics of the unemployed that can be tracked over time we used the following procedure. We first estimated a wage regression using data from 2004-06, which was a more or less "normal" period for the labor market, and then we combined the coefficients from this regression with the characteristics of either the short-term unemployed or long-term unemployed each year to track their earnings potential each year from 1995 to 2013. Specifically, the wage regression related the log hourly wage of workers to their education, experience, industry, occupation, race, gender, and marital status. ${ }^{5}$ The estimated coefficients from this regression were then combined with the characteristics of those on shortterm unemployment spells ( 26 weeks or less at the time of the survey) or

5. We use four categorical variables for highest level of educational attainment: less than high school, high school only, some college/associate degree, and bachelor's degree or higher. We include linear and quadratic terms in potential experience. Also included in the regression are dummy variables for female, married, widowed/divorced, Hispanic ethnicity, white, black, 10 major industries, and 11 major occupations, as well as an indicator for new entrants (who lacked an industry and occupation). 
Figure 2. Mean Predicted Wages for the Unemployed by Duration of Unemployment, 1994-2013a

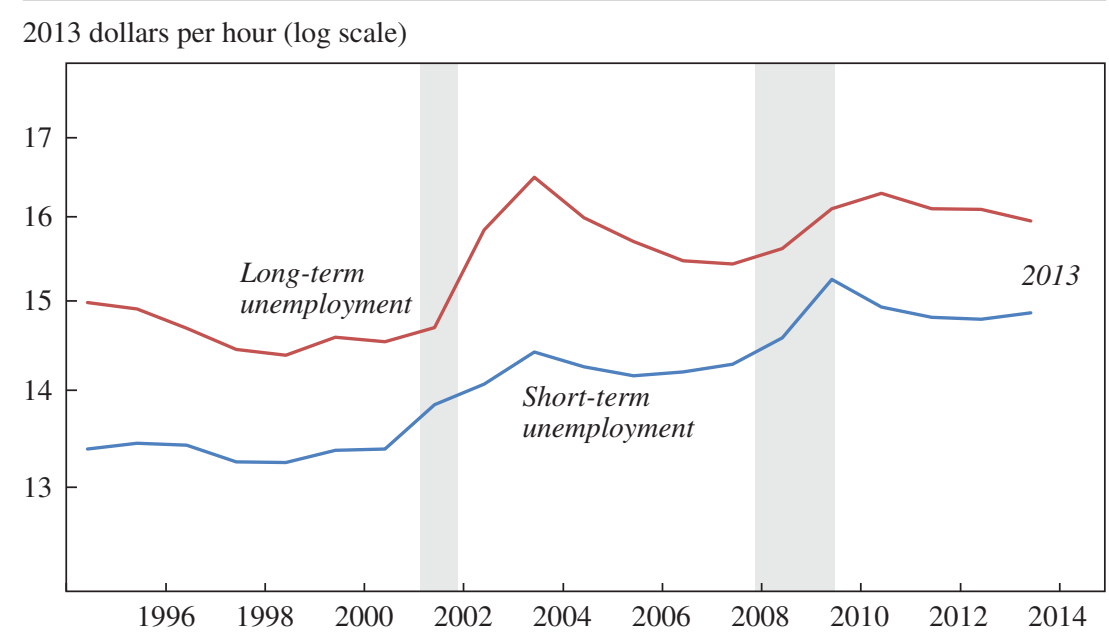

Source: Bureau of Labor Statistics; National Bureau of Economic Research; authors' calculations using Current Population Survey Longitudinal Population Database (see Nekarda 2009).

a. Mean predicted hourly wages for the unemployed (annual averages) based on their characteristics. Shading denotes recessions.

on long-term unemployment spells (more than 26 weeks at the time of the survey) each year to derive a simple summary of the composition of the long-term unemployed with respect to their earnings prospects. ${ }^{6}$

Figure 2 contains the results of this exercise. The long-term unemployed are predicted to have higher earnings than the short-term unemployed, in large part because they are older and have higher potential work experience. They are also predicted to earn about 10 percent less than the average employed person in 2013. There appears to be both a mild secular trend and a mild cyclical pattern in the composition of both the short-term and long-term unemployed, at least as far as their characteristics that predict earnings are concerned. The composition of the unemployed has gradually tilted towards those with characteristics associated with higher earnings, such as more education, since the mid-1990s.

The mix of the long-term unemployed with characteristics associated with higher earnings tends to rise during economic downturns. Predicted

6. We use CPS data from 1995 forward because we limit the sample to the period after the 1994 redesign of the CPS, which affected the share of long-term unemployed workers (Polivka and Miller 1994) and improved the ability to track individuals over time. 
earnings of both the short-term and long-term unemployed rose by an average of 6 percent around the time of each of the two previous recessions. This pattern is consistent with Andreas Mueller's (2012) finding that in recessions the pool of the unemployed tends to shift toward those with higher earnings in their previous jobs, because such workers are more likely to be displaced in recessions. The cyclical movements for the longterm unemployed slightly lag behind those for the short-term unemployed, probably because some of the short-term unemployed become long-term unemployed over time.

These findings complement Kroft and others' (2014, p. 8) conclusion that when the permanently laid-off share is included, "compositional changes in the unemployed account for virtually none of the observed rise in long-term unemployment" during and after the Great Recession. In the section on transition rates below, we perform a similar exercise to examine changes in the composition of the unemployed with respect to their measured characteristics that predict job finding and labor force withdrawal.

\section{Transition Rates: Current Population Survey Data}

This section explores the labor market transitions of the unemployed over time. Specifically, we use longitudinally linked CPS data (see Nekarda 2009) to study how the long-term unemployed fare in later survey months. Because of limitations in the matched CPS data, such as the failure to track individuals who move to new locations, we supplement this analysis with the SIPP and Work Trends Survey in sections IV and V.

We are most interested in documenting the cyclical pattern of transitions from unemployment to either employment or out-of-the-labor-force by duration of unemployment, and we focus on monthly transitions as well as those over a year or longer. As others have shown (Valletta 2011), the longterm unemployed have different labor market flows compared to short-term unemployed workers. We do not find any evidence that compositional changes over the business cycle account for cyclical swings in job finding rates or labor force withdrawal rates among the unemployed. The results suggest that a critical channel for the future path of long-term unemployment in the United States involves the evolution of labor force withdrawal rates by duration of unemployment over the business cycle. We will later embed different assumptions about movement from unemployed status to being out of the labor force into a calibration model along the lines of Kroft and others (2014) to explore the role of labor force exits in the evolution of long-term unemployment and the Beveridge curve. 
Figure 3. Monthly Probability of Transitioning from Unemployment to Employment by Duration of Unemployment, 1994-2013a

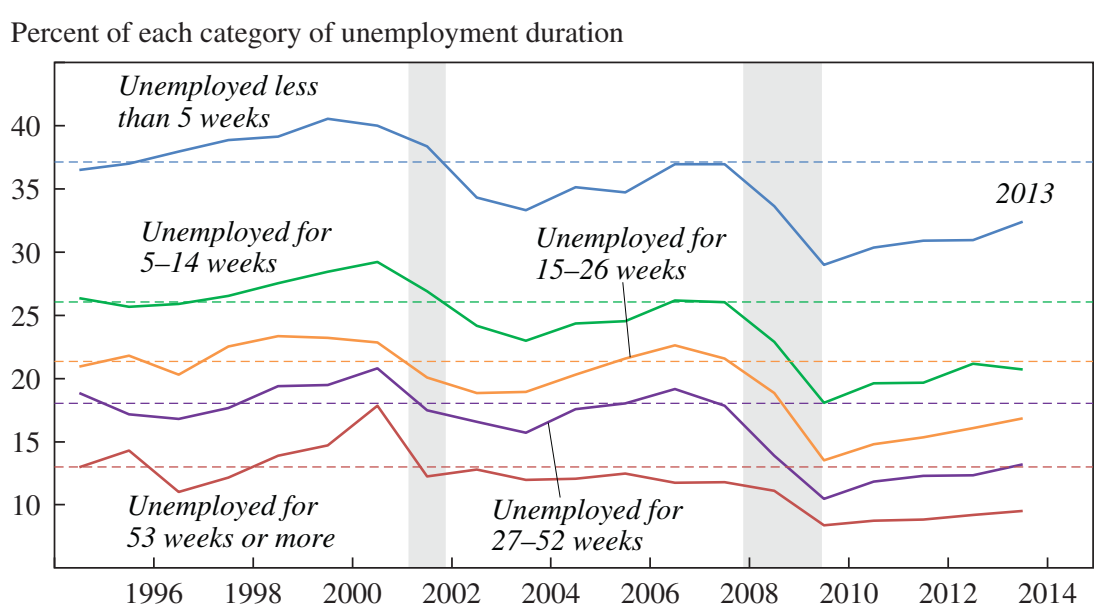

Source: Bureau of Labor Statistics (Current Population Survey); National Bureau of Economic Research. a. Dashed lines represent 1994-2007 averages. Shading denotes recessions.

Figure 3 displays annual averages of monthly transition rates from unemployment to employment each year since 1994, based on BLS's published transition rates for five duration-of-unemployment categories. Many researchers have documented that CPS data can severely misstate gross labor market flows because of classification errors, which means one must use caution in interpreting the data. For instance, studies based on re-interview data from the CPS in which respondents are re-interviewed about one week after their initial interview have found that a person's reported labor force status can be wildly inconsistent. ${ }^{7}$ If such classification errors are not perfectly serially correlated, then a nontrivial share of individuals may switch labor force status over time solely because of reporting errors in one month, which will tend to inflate transition rates computed from the CPS. Nonetheless, the CPS series conveys a signal about relative transition rates (both over time and across unemployment durations) and underlying movements in the official unemployment rate.

A few patterns are clear. First, the job finding rate is lower for those with a longer duration of unemployment, with the long-term unemployed 
finding jobs at less than half the rate of those who are very-short-term unemployed. Second, the cyclicality of job finding is clear in these data, with all rates declining during the recession of the early 2000s, and declining more dramatically during the Great Recession. Third, job finding rates for all groups remain well below their pre-Great Recession averages. Fourth, the job finding rate has risen for each group in the last 4 years, although it has barely increased for those unemployed longer than a year. In 2013, just under 10 percent of those who had been unemployed for more than one year transitioned into employment in the average month. This rate, though higher than in many European countries (Elsby and others 2011), might overstate the prospects of the long-term unemployed due to classification errors and the fact that the long-term unemployed are particularly likely to take lower-paying, part-time jobs and temporary jobs; a point we revisit below.

The observed duration dependence in job finding rates could reflect worker heterogeneity (that is, that those with the most marketable skills tend to find jobs more quickly), or it could also be an effect of discouragement, skill erosion, and employer statistical discrimination against the long-term unemployed. Available evidence on the respective roles of heterogeneity and duration dependence on unemployment hazard rates remains unsettled. On the one hand, econometric evidence that tries to model the distribution of unobserved heterogeneity tends to find that observed duration-dependent transition rates are not primarily a result of heterogeneous job searchers (Heckman and Singer 1984). Consistent with this interpretation is evidence showing that employers are less likely to call in workers for an interview if they have a jobless spell in their resumes (Kroft and others 2014; and Ghayad 2013), as well as evidence that the amount of time unemployed workers devote to searching for a job declines the longer they are unemployed (Krueger and Mueller 2011 and Wanberg and others 2012). On the other hand, studies have found nearly constant reemployment hazard functions if workers who are recalled to their previous job are removed from the sample (Katz 1986, Katz and Meyer 1990, and Fujita and Moscarini 2013). We next examine whether the cyclical pattern of job finding rates is consistent with changes in observed worker heterogeneity and later turn to the issue of recall.

Figure 4, which uses the same scale for the $y$-axis as figure 2, suggests that any effect of changing worker heterogeneity on the pattern of job finding rates over the business cycle for the long-term unemployed is very small. To construct this figure, we first estimated a logistic model in which the dependent variable was 1 if a worker who was unemployed in month $t$ 
Figure 4. Mean Predicted Probability of Transitioning from Unemployment to Employment for the Unemployed Based on Their Characteristics, by Duration of Unemployment, 1994-2013

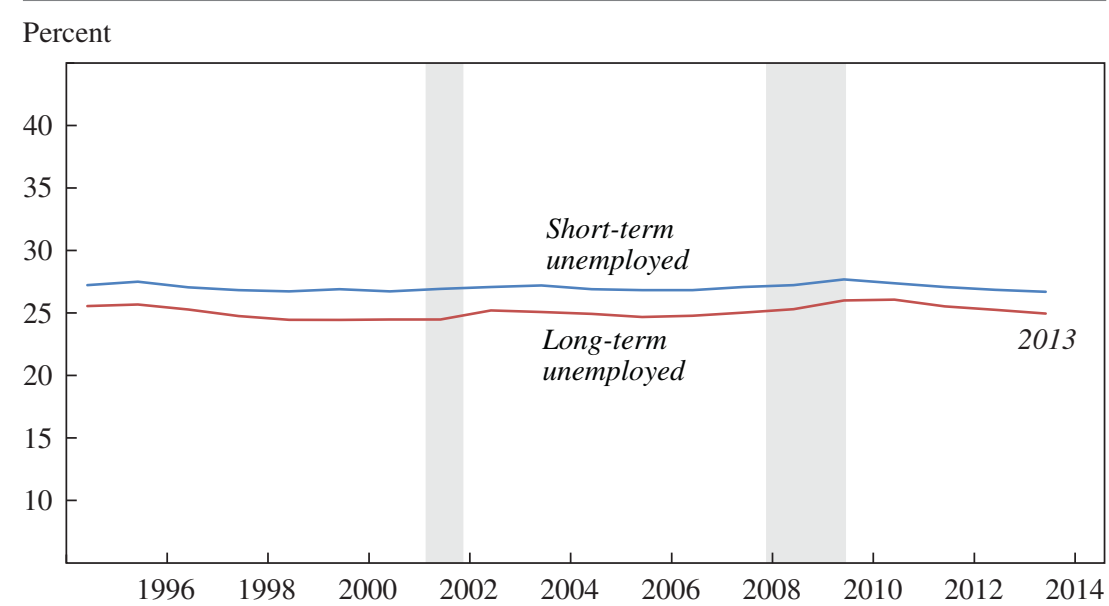

Source: National Bureau of Economic Research; authors' calculations using Current Population Survey Longitudinal Population Database (see Nekarda 2009).

a. Annual averages. Shading denotes recessions. Predicted transition rate was derived by estimating a logistic model where the dependent variable was one if a worker who was unemployed in month $t$ was classified as employed in month $t+1$, and zero otherwise (i.e., if the worker remained unemployed or exited the labor force). Explanatory variables were: education, experience, industry, occupation, race, new entrant status, gender, and marital status. The model was estimated for the years 2004-06. The estimated coefficients from this model were then combined with the characteristics of the long-term unemployed (defined as those unemployed for longer than 26 weeks at the time of the survey) and short-term unemployed each year to predict the probability of transitioning to employment in the next month.

was classified as employed in month $t+1$, and 0 otherwise (that is, if the worker remained unemployed or exited the labor force). The explanatory variables were the same characteristics that were used to predict wages in figure 2 (see footnote 6). The model was estimated for the years 2004-06. We then used the coefficients from this model to predict the job finding rate of the short-term (26 weeks or less) and long-term (27 weeks or longer) unemployed based on their characteristics each year.

The cyclical pattern suggests that there is a very slight shift in the characteristics of the long-term unemployed in recessionary periods toward those that are more favorable for finding a job, but the shift in the composition is modest, predicting a rise in the job finding rate of only about 1 to 2 percentage points. This is in contrast to the roughly 5-percentage-point fall in the job finding rate for the long-term unemployed in the past two recessions. The shift in composition of the short-term unemployed is even smaller than that of the long-term unemployed. 
Notice also that the predicted job finding rate for the long-term unemployed based on their characteristics is around 25 percent according to figure 4 . However, figure 3 shows that the job-finding rate for the longterm unemployed is consistently well below that rate, even in periods of a relatively strong job market. (In 2004-06, for example, the average monthly job finding rate for those unemployed longer than 26 weeks was 16 percent.) This overprediction is consistent with the view that the long-term unemployed face discrimination in the job market or become discouraged and search less intensively, or that they possess unobserved characteristics that lead to lower job finding prospects-or some combination of all three.

The short-term unemployed are predicted to have a slightly higher jobfinding rate than the long-term unemployed. In contrast to the long-term unemployed, the predictions for the short-term unemployed are slightly below their actual average job finding rate (29 percent) in 2004-06.

Figure 5 displays the monthly labor force withdrawal rates for the unemployed in each of the duration groups from 1994 to 2013. A few patterns are noteworthy. First, the long-term unemployed tend to have a higher rate of labor force exit than the short-term unemployed, perhaps partly reflecting their discouragement. ${ }^{8}$ Second, labor force exit rates tend to drop in a recession, especially for the long-term unemployed. Indeed, in the mild recession of the early 2000s, the labor force exit rate for the long-term unemployed fell by almost 10 percentage points to about the same level as the rate for recently unemployed workers. Likewise, in the deep recession in 2008-09 the labor force withdrawal rate for the long-term unemployed again fell by around 10 percentage points, to virtually the same level as that of the short-term unemployed. Third, the labor force exit rate gradually rises for all duration groups after a recovery takes hold, and the rate rises more for the long-term unemployed. In other words, after labor force exit rates collapse in recessions to about the same level for all duration groups, they tend to move back in recoveries toward their historical norms, with a higher exit rate for the long-term unemployed.

Figure 6 suggests that a relatively small part of the cyclical pattern in the labor force exit rate for the long-term unemployed is due to compositional

8. This contrast does not appear to result from the labor force status of the long-term unemployed being more fluid from month to month than that of the short-term unemployed. Once they exit the labor force, the long-term and short-term unemployed have about the same probability of remaining out of the labor force. Over the period from 1994-2013, for example, we calculate that a worker who was long-term unemployed in his or her first survey month and then exited the labor force in the second survey month had a 64 percent chance of being out of the labor force in the third survey month. The corresponding figure for the short-term unemployed was very similar: 62 percent. 
Figure 5. Monthly Probability of Transitioning from Unemployment to Out of the Labor Force, by Duration of Unemployment, 1994-2013a

Percent of each category of unemployment duration

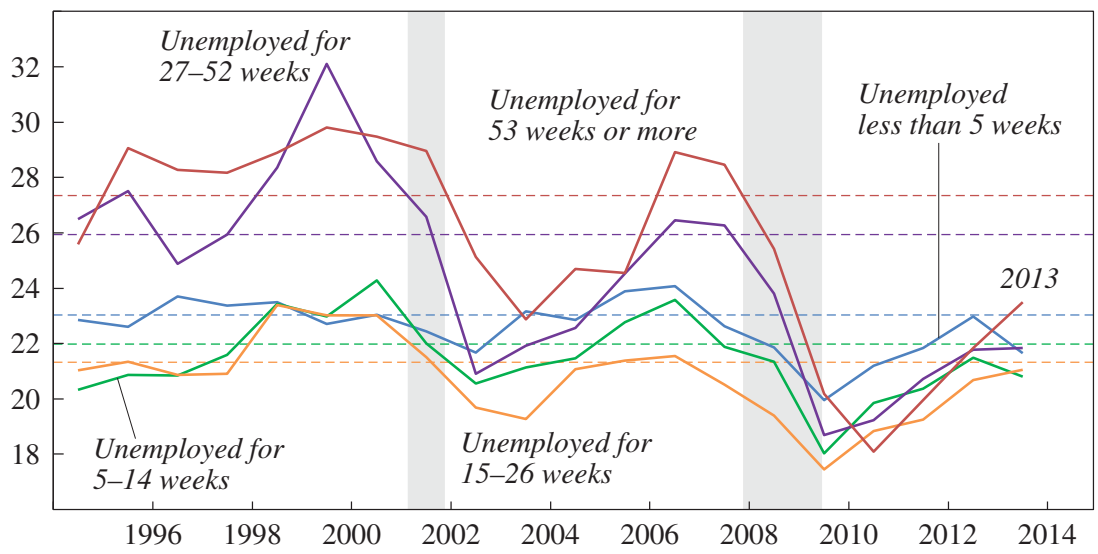

Source: Bureau of Labor Statistics (Current Population Survey); National Bureau of Economic Research. a. Dashed lines represent 1994-2007 averages. Shading denotes recession.

Figure 6. Mean Predicted Probability of Transitioning from Unemployment to Out of the Labor Force for the Unemployed Based on Their Characteristics, by Duration of Unemployment, 1994-2013

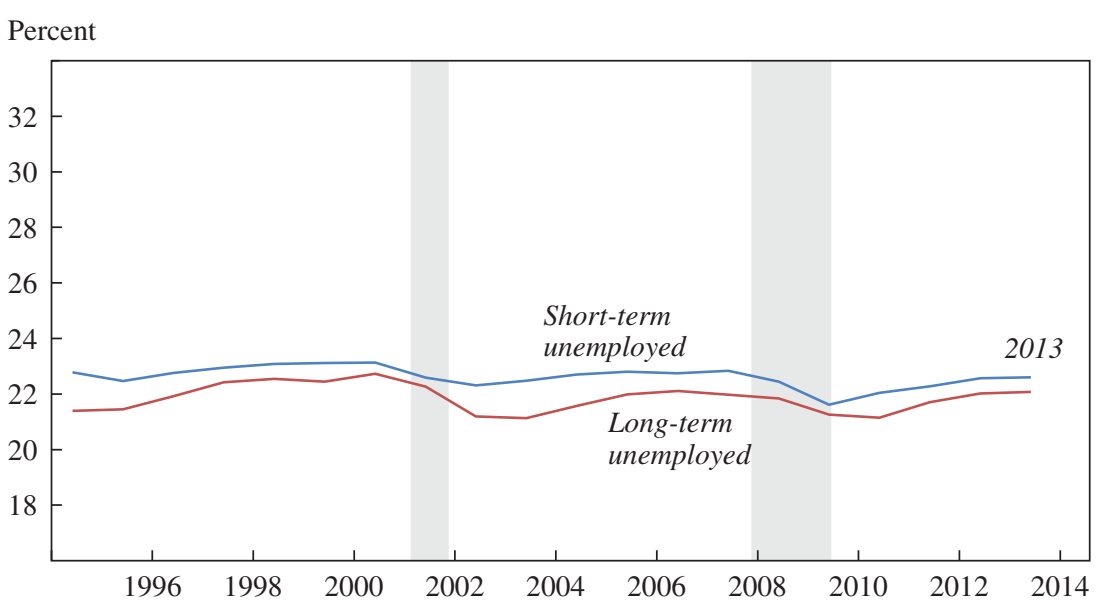

Source: National Bureau of Economic Research; authors' calculations using Current Population Survey Longitudinal Population Database (see Nekarda 2009).

a. Annual averages. Shading denotes recessions. Predicted transition rate was derived by estimating a logistic model where the dependent variable was 1 if a worker who was unemployed in month $t$ was classified as out of the labor force in month $t+1$, and zero otherwise (i.e., if the worker remained unemployed or was classified as employed). Explanatory variables were education, experience, industry, occupation, race, new entrant status, gender, and marital status. The model was estimated for the years 2004-06. The estimated coefficients from this model were then combined with the characteristics of the long-term unemployed (defined as those unemployed for longer than 26 weeks at the time of the survey) and the short-term unemployed each year to predict the probability of transitioning out of the labor force in the next month. 
shifts and that for the short-term unemployed this is an even smaller factor. The figure shows the predicted unemployment-to-out-of-the-labor-force transition rates based on the same characteristics and approach used to construct figure 4. Again, the scale is the same as in figure 5. There is a cyclical pattern in the composition of the unemployed, with those more strongly attached to the labor force being more likely to be among the unemployed during a recession. Nevertheless, movements in composition would predict only about a 2-percentage-point decline in the labor force withdrawal rate for the long-term unemployed in a recession, in contrast with the roughly 10-percentage-point drop observed in the last two recessions. Over the 1994-2013 period, changes in the predicted labor force withdrawal rate of long-term unemployed workers due to shifts in their characteristics account for 18 percent of the total variation in the observed labor force withdrawal rate. This suggests that compositional shifts are responsible for part, but by no means all, of the time-series pattern of labor force attachment of the long-term unemployed shown in figure $5 .{ }^{9}$

Labor force exits and their effect on the unemployment rate have often been neglected in past research, although recent work by Elsby, Hobijn, and Şahin (2013) suggest that changes in the participation margin account for 33 percent of the cyclical variation in the unemployment rate. We return to this issue in the calibration exercise at the end of the paper.

As mentioned earlier, during the most recent recession and similarly to the recession of the early 2000s, the rate of labor force withdrawal dropped for all durations of unemployment, but most markedly for the long-term unemployed, and only a small part of this drop was a result of compositional shifts. This phenomenon probably reflects, in part, the extension of unemployment insurance benefits, which require workers to search for a job and have been found to induce unemployed workers to stay in the labor force, thus elevating the measured unemployment rate (see Rothstein 2011 and Farber and Valletta 2013). Many commenters have predicted that as these benefits are exhausted or scaled back, the withdrawal rate for the long-term unemployed may begin to rise toward its historical average. By 2013 it appeared that this process had begun to take place for those who

9. This is based on calculating $1-\frac{\sum\left(y_{t}-\hat{y}_{t}\right)^{2}}{\sum\left(y_{t}-\bar{y}\right)^{2}}$, where $y_{t}$ is the observed labor force withdrawal rate in year $t, \hat{y}_{t}$ is the predicted rate from the logit equation combined with the characteristics of the long-term unemployed in year $t$, and $\bar{y}$ is the mean labor force withdrawal rate. Using the 1994-2013 data, this value equals 0.18 . 
had been unemployed for more than one year, but it was less apparent for those who had been unemployed between 27 and 52 weeks.

As shown in the simulations below, the movement of the labor force withdrawal rates of the long-term unemployed toward their historical averages has important implications for the unemployment rate and, relatedly, for the Beveridge curve. Nevertheless, barring an extraordinarily fast rebound in the labor force exit rates of the long-term unemployed relative to their short-term unemployed counterparts, it appears likely that the long-term unemployment rate will remain persistently high for a considerable time.

\section{Longer-Term Transitions}

To investigate more fully whether the long-term unemployed are on the margins of the labor market, we also look at transition rates for the longterm unemployed over longer periods of time using matched data from the CPS. In the CPS's rotation group design, individuals are interviewed for 4 consecutive months, then dropped out of the survey for 8 months, and then interviewed again for 4 more months. This design makes it possible to examine transitions over a 15-month interval. A monthly job finding rate of 10 to 15 percent for the long-term unemployed would exaggerate their connection to employment if random classification errors in labor force status inflate their transition rates or if the long-term unemployed tend to work in transitory jobs if they do become reemployed, as Ann Stevens (1997) finds. One way to assess the importance of these issues, and obtain an alternative indicator of the extent to which the long-term unemployed are connected to the labor market, is to examine transition rates over a longer period of time. ${ }^{10}$

Indeed, the actual long-term transition rates are considerably lower than those implied by monthly data. ${ }^{11}$ As figure 7 (upper panel) illustrates, since the beginning of the Great Recession, 36 percent of those who were long-term unemployed in a given month were employed 15 months

10. Although classification errors will still bias job finding rates upward over a longer span of time, these errors only affect the first and last month of reported data and thus do not compound over the intervening months. By contrast, the impact of classification errors is magnified if monthly transition rates are used to compute longer-term transition rates, because the errors affect each monthly rate and thus compound over time.

11. Assuming independence and a constant 0.10 probability of finding a job in any given month, the proportion of unemployed workers who gained employment within 15 months would be $1-(1-0.10)^{15}=0.79$. 
later; in comparison, 34 percent were not in the labor force and 30 percent were unemployed. Furthermore, of the 36 percent who were employed 15 months later, less than one-third had been employed full-time for 4 consecutive months. As a result, from 2008 to 2012, only 11 percent of those who were long-term unemployed in a given month returned to full-time, steady employment a year later. ${ }^{12}$ If we include months of parttime employment, only 24 percent of long-term unemployed workers were reemployed for 4 consecutive months starting a year later.

If the experience of long-term unemployment weakens individuals' labor market prospects, one would expect to see a difference in labor market outcomes between the short- and long-term unemployed. Figure 7 (lower panel) also shows the comparable figures for the short-term unemployed. Although the difference between their job finding rates and those of the long-term unemployed is 13.6 percentage points, the difference between these two groups in finding full-time, steady employment one year later is 3.6 percentage points. Still, with either measure, the CPS data indicate that over a 15-month span the job-finding hazard rate is about 25 percent lower for the long-term unemployed than the short-term unemployed. Although the short-term unemployed have struggled to find employment in this period, the long-term unemployed have faced even worse prospects.

Figure 8 provides a further disaggregated look at the transitions of the long-term unemployed, which highlights the transitory nature of their employment opportunities. In particular, the diagram divides the data by labor market status in the 2nd, 3rd, and 4th months in the sample. The first noteworthy observation from this figure is that only 22 percent of the longterm unemployed in month 1 report being employed for 1 month or more in months 2 through 4 . This compares to 11 percent who report being out of the labor force in months 2 through 4 , and 67 percent who report having been unemployed in at least 1 month between months 2 and 4 without ever moving to employment. Once the long-term unemployed leave the labor force for 3 straight months they are likely to stay out of the labor force, with only about 32 percent reentering; a slightly larger share move into employment than into unemployment, consistent with Barnichon and Figura (2013), who examined all nonparticipants who subsequently entered the labor force.

12. Full-time, steady employment in this context means that someone who had been unemployed for 27 weeks or longer in month $t$ was employed full-time for 4 consecutive months starting in month $t+12$. Throughout our analysis, we count the self-employed as employed. 
Figure 7. Longitudinal Transition Rates by Duration of Unemployment, 2008-13

\section{Longitudinal transition rates for the long-term unemployed, 2008-13}

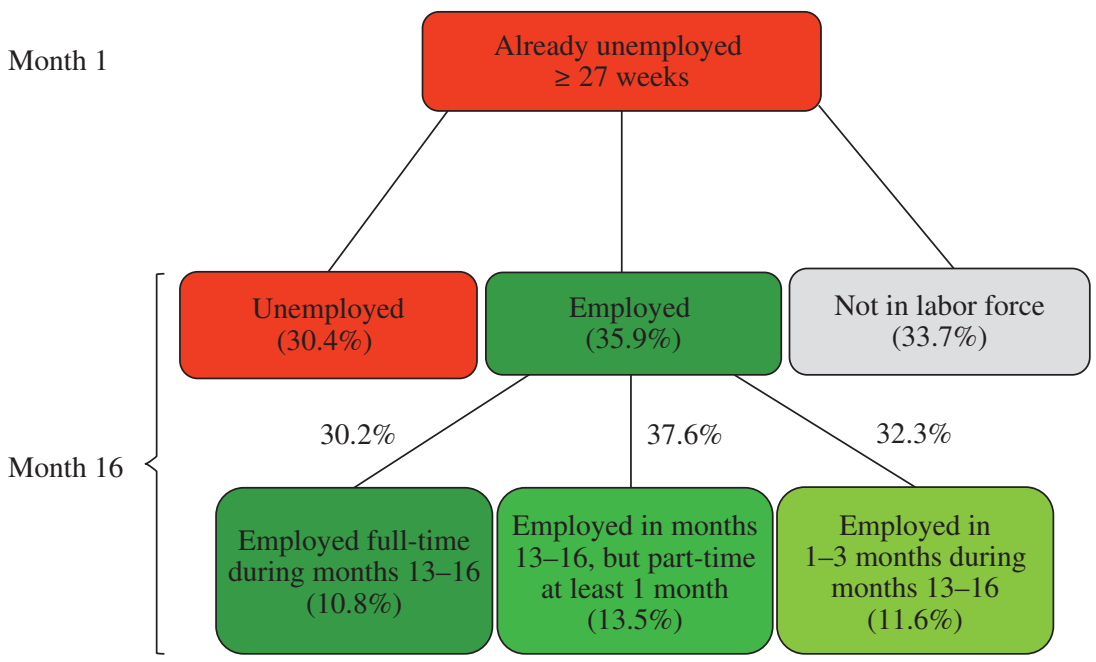

\section{Longitudinal transition rates for the short-term unemployed, 2008-13}

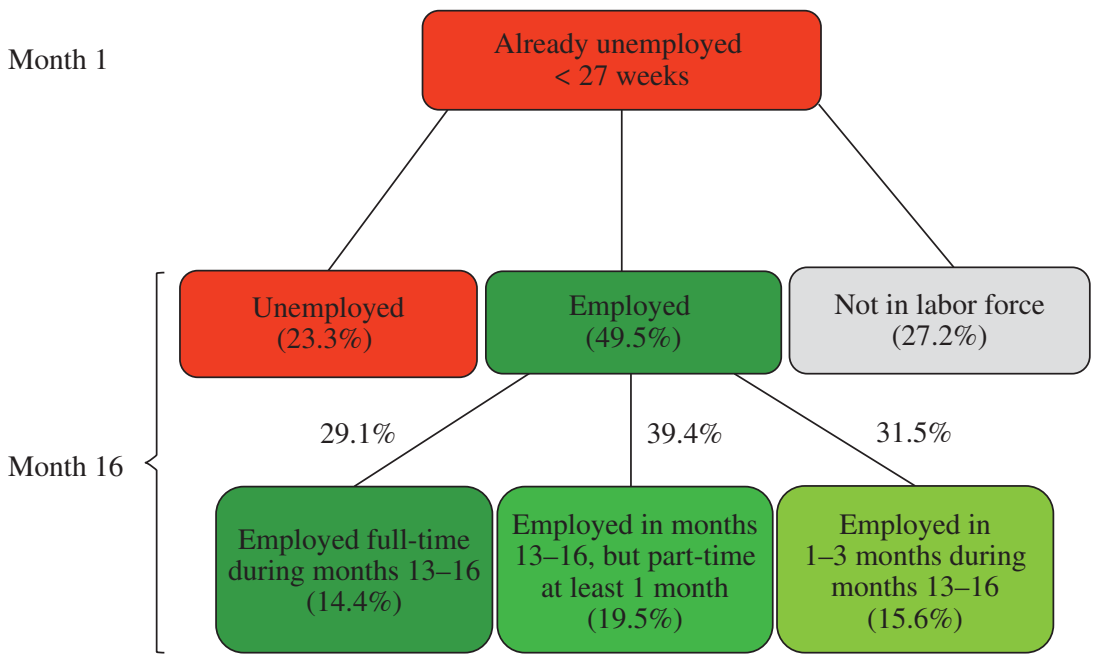

Source: Authors' calculations using Current Population Survey Longitudinal Population Database (see Nekarda 2009).

Note: Chart reflects the experience of those who were long-term unemployed in their first Current Population Survey interview (2008-12) and their labor force status 15 months later (2009-13). 
Figure 8. Longitudinal Transition Rates for the Long-Term Unemployed, 2008-13

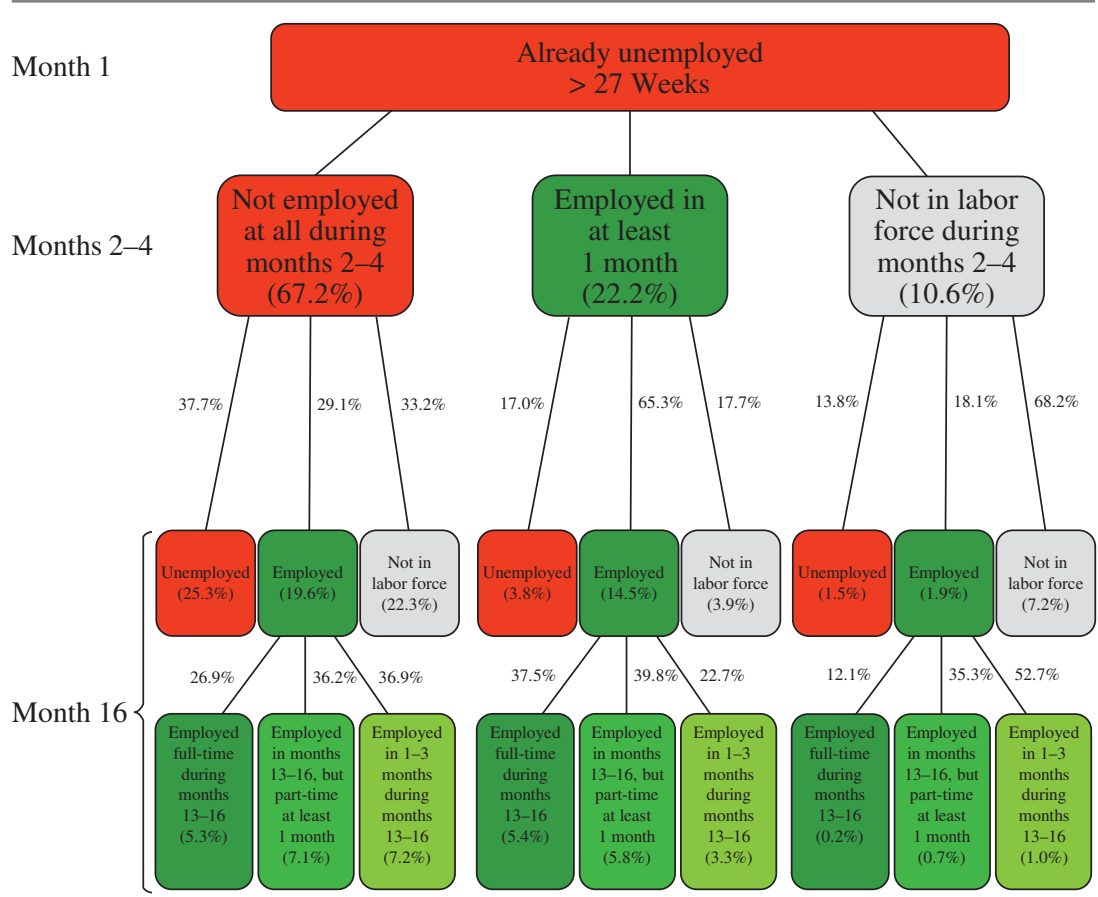

Source: Authors' calculations using Current Population Survey Longitudinal Population Database (see Nekarda 2009).

Note: Chart reflects the experience of those who were long-term unemployed in their first Current Population Survey interview (2008-12) and their labor force status 15 months later (2009-13).

Those who did regain employment a year after exiting the labor force for 3 straight months were mostly employed intermittently or in part-time jobs. Only 2 percent of those who exited the labor force for 3 straight months were employed in full-time jobs for 4 consecutive months a year later.

Of the 22 percent who were employed in at least one of months 2 through 4 after having been long-term unemployed in the 1st survey month, 65 percent were also employed in month 16 . But, even for this latter group, steady, full-time employment was not as prevalent as might be expected. Those who were jobless in months 2 through 4 displayed similar behavior to those who were initially long-term unemployed, as illustrated in figure 7 (upper panel), although with slightly more movement into unemployment than into employment and not in the labor force. All of these results underscore the fact that the long-term unemployed face difficulty regaining fulltime, steady work over the longest period we can observe in CPS data. It 
Figure 9. Probability of Transitioning from Unemployment to Employment after 15 Months, by Duration of Unemployment, 1982-2012a

Percent of total labor force status flows

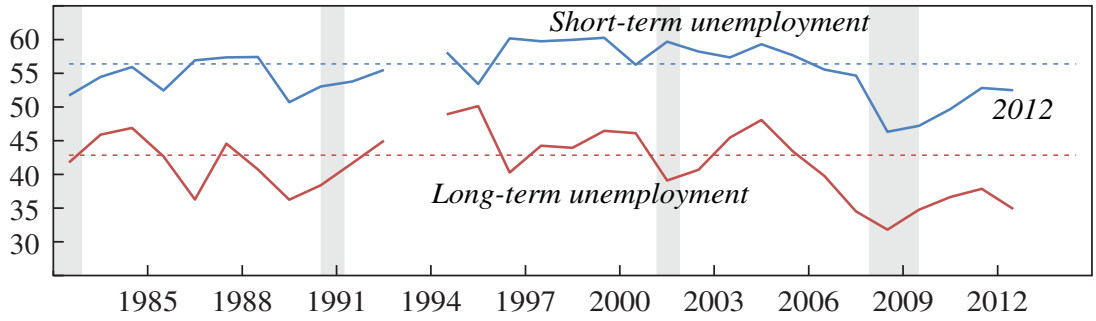

Source: Authors' calculations using Current Population Survey Longitudinal Population Database (see Nekarda 2009); National Bureau of Economic Research.

a. Dashed lines represent 1982-2007 averages. Shading denotes recession. Year on $x$-axis represents the survey entry year. There is no observation for 1993 due to survey redesign and CPS matching difficulties.

Figure 10. Probability of Transitioning from Unemployment to Full-Time, Steady Employment in Months 13-16, by Duration of Unemployment, 1982-2012

Percent of total labor force status flows

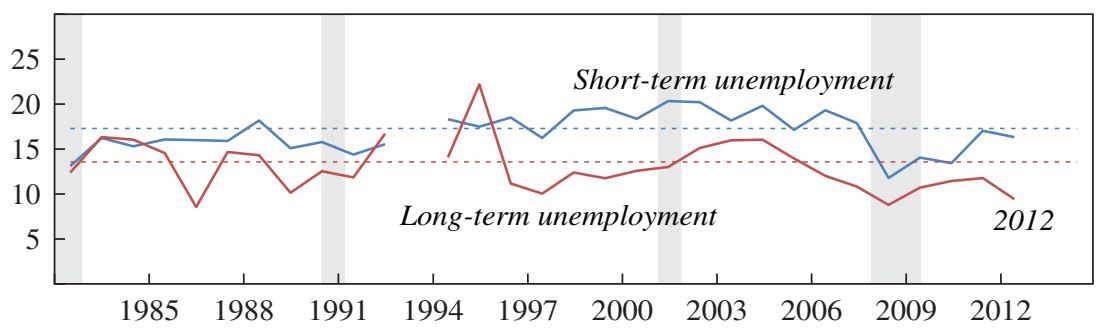

Source: Authors' calculations using Current Population Survey Longitudinal Population Database (see Nekarda 2009); National Bureau of Economic Research.

a. See figure 9 notes for details.

appears that reemployment does not fully reset the clock for the long-term unemployed.

\section{III.A. 15-Month Transition Rates over Time}

Figure 9 shows the probability of moving to employment 15 months later for those who were classified as short-term unemployed (less than 27 weeks) or long-term unemployed (27 weeks or longer) in the initial survey month. (Time on the $x$-axis indicates the year of the initial survey.) Figure 10 provides the corresponding data for the likelihood of holding a full-time job for 4 consecutive months a year later by initial duration of 
Figure 11. Probability of Transitioning from Unemployment to Out of the Labor Force after 15 Months, by Duration of Unemployment, 1982-2012a

Percent of total labor force status flows

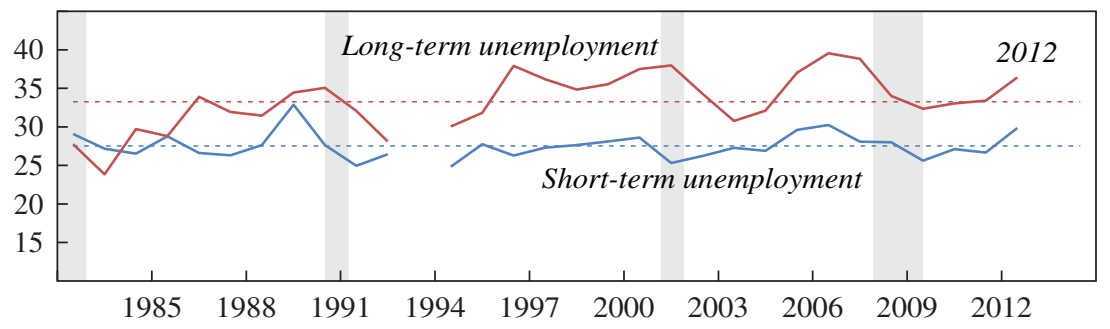

Source: Authors' calculations using Current Population Survey Longitudinal Population Database (see Nekarda 2009); National Bureau of Economic Research.

a. See figure 9 notes for details.

unemployment, and Figure 11 contains the corresponding information for the likelihood of transitioning out of the labor force 16 months later. To lengthen the sample period, the figures begin with the 1982 CPS survey, although it is possible that the 1994 CPS redesign affected the data.

A few observations from these figures are noteworthy. First, over the entire 30-year period, the short-term unemployed are more likely to transition into employment (by either measure) than the long-term unemployed. As a percentage of long-term unemployed workers' job finding rates, the differences are sizable, nearly 20 to 30 percent depending on the measure. However, in terms of levels, the differences in rates are not as great as one might expect if the long-term unemployed were distinctly more disconnected from the job market than the short-term unemployed (for example, in the last recovery 19 percent of the short-term unemployed were in steady, full-time jobs a year later as compared with 14 percent of the longterm unemployed).

Second, over the whole period, the long-term unemployed are, on average, 6 percentage points more likely to exit the labor force 15 months after the initial survey than are the short-term unemployed. The gap in the exit rate between the short-term and long-term unemployed narrows leading up to and coming out of a recession, and it grows during recoveries.

Lastly, we examine the cyclicality of the long-term transition rates. ${ }^{13}$ The figures indicate a pronounced drop in labor force exits around recessions

13. There is a long history of studying the cyclicality of the monthly job finding rate for the unemployed in CPS data. Important recent contributions are Elsby, Michaels, and Solon (2009) and Shimer (2012). For the most part, that literature does not distinguish between short-term and long-term unemployed workers. 
Table 2. Cyclicality of Longer-Term Transitions: Regressions on Unemployment Rate

Full sample $(N=30)$

Transition rate (dependent variable):

\begin{tabular}{lcccc}
\cline { 2 - 5 } Group & $U-U$ & $U-O$ & $U-E$ & $U-F T S E^{\mathrm{b}}$ \\
\hline Short-term unemployed & $0.106 * * *$ & -0.007 & $-0.031^{* * * *}$ & $-0.062^{* * *}$ \\
& $(0.019)$ & $(0.006)$ & $(0.006)$ & $(0.008)$ \\
Long-term unemployed & $0.096^{* * *}$ & $-0.041^{*}$ & -0.026 & -0.014 \\
& $(0.013)$ & $(0.017)$ & $(0.015)$ & $(0.023)$ \\
\hline
\end{tabular}

Instrument for unemployment rate with previous year's unemployment rate $(N=30)$

Transition rate (dependent variable):

\begin{tabular}{lcccc}
\cline { 2 - 5 } Group & $U-U$ & $U-O$ & $U-E$ & $U-F T S E^{\mathrm{b}}$ \\
\hline Short-term unemployed & $0.070^{* *}$ & -0.004 & -0.017 & $-0.044^{*}$ \\
& $(0.021)$ & $(0.007)$ & $(0.010)$ & $(0.018)$ \\
Long-term unemployed & $0.075^{* * *}$ & $-0.061^{*}$ & 0.005 & 0.026 \\
& $(0.020)$ & $(0.028)$ & $(0.027)$ & $(0.040)$ \\
\hline
\end{tabular}

Pre-2008 sample $(N=25)$

Transition rate (dependent variable):

\begin{tabular}{lcccc}
\cline { 2 - 5 } Group & $U-U$ & $U-O$ & $U-E$ & $U-F T S E^{\mathrm{b}}$ \\
\hline Short-term unemployed & $0.089 * * *$ & -0.007 & $-0.022 * * *$ & $-0.063 * * *$ \\
& $(0.022)$ & $(0.010)$ & $(0.004)$ & $(0.007)$ \\
Long-term unemployed & $0.097 * * *$ & $-0.073 * * *$ & 0.001 & 0.031 \\
& $(0.017)$ & $(0.009)$ & $(0.010)$ & $(0.016)$
\end{tabular}

Source: Bureau of Labor Statistics; authors' calculations using Current Population Survey Longitudinal Population Database (see Nekarda 2009).

a. Table reports coefficient on unemployment rate from bivariate regression of log of transition rate on unemployment rate. Unemployment rate is the average of the rate in the year of the initial CPS survey year and the following year. Annual data for those who entered the survey from 1982 to 2012 . No matched data are possible for those who entered the CPS in 1993 because of the CPS redesign. Newey-West standard errors (with 3 lags) shown in parentheses.

Statistical significance at the $* * * 0.1$ percent, $* * 1$ percent, and $* 5$ percent levels.

b. FTSE is full-time, steady employment in months 13 to 16 of the survey.

for the long-term unemployed and a sharp drop in the job finding measures during recessions for the short-term unemployed. To summarize the cyclicality of the longer-term labor force transition rates by duration of unemployment, the top panel of table 2 reports results of bivariate regressions, in which the dependent variable is the logarithm of the various 15-month transition rates for those who became unemployed in year $t$ and the explanatory variable is the unemployment rate, averaged over years $t$ and $t+1$. The sample covers the period 1982 to 2013 (initial CPS surveys 1982 to 2012). 
Consistent with the figures, the short-term unemployed display more of a procyclical relationship when it comes to job finding, especially for finding a steady, full-time job a year later. A 3-percentage-point drop in the unemployment rate, for example, is associated with a modest 20 percent increase in the transition rate into steady, full-time employment for the short-term unemployed. For the long-term unemployed, the coefficient on the unemployment rate in the regression for their transition to steady, fulltime employment is statistically insignificant and small. Moreover, a $t$-test rejects the null hypothesis that the short-term and long-term unemployed have the same coefficient on the unemployment rate (two-tailed p-value $=$ 0.04). Also, consistent with the visual impression from the figures, the labor force exit rate for the long-term unemployed is significantly and negatively related to the unemployment rate, while the relationship is insignificant and close to zero for the short-term unemployed.

One concern with the descriptive regressions in table 2 is that the unemployment rate is partly determined by the flow rates that are the outcome variables of the models. To avoid the possibility of mechanical simultaneity bias, the lagged unemployment rate (that is, the year $t-1$ unemployment rate) was used as an instrumental variable for the average unemployment rate in years $t$ and $t+1$. The results, presented in the middle panel of table 2, are qualitatively similar to those that used the average unemployment rate in the initial year and subsequent year, allaying concerns that simultaneity bias is responsible for the patterns in the upper panel.

Another possible concern is that the regression results are dominated by the period since the start of the Great Recession, when unemployment rose sharply. To address this issue, the bottom panel of table 2 presents results where the sample is truncated in 2007. Again, the findings are similar. Indeed, the coefficient on the unemployment rate is positive but statistically insignificant in the regressions for both measures of employment for the initially long-term unemployed workers.

We performed some additional robustness checks of the results in table 2 . For example, in various models we included a time trend, included a dummy variable for the period before the CPS redesign, estimated the regressions with the transition rates in levels instead of logs, and limited the sample to the period after the CPS redesign but before the Great Recession. In all of these cases, we find results that are qualitatively similar to those in table 2.

As a whole, this analysis of annual transition rates suggests that a stronger macroeconomy is only mildly associated with the likelihood of steady, full-time employment being regained by the long-term unemployed, and somewhat more strongly associated with similar employment being 
regained by the short-term unemployed..$^{14}$ The long-term unemployed appear to be more insulated from the beneficial effects of a high-pressure labor market than the short-term unemployed. While a stronger economy appears to help the long-term unemployed to transition into some kind of employment, it does not seem to provide much help when it comes to finding steady, full-time employment.

\section{III.B. The Meaning of "Not in the Labor Force" for the Long-Term Unemployed}

As shown earlier, in recent years the long-term unemployed were slightly more likely to have left the labor force after 15 months than to have remained unemployed. We next explore the activities of the long-term unemployed when they report that they leave the labor force. This provides some purchase on whether those who exit the labor force are likely to seek employment if conditions improve and, therefore, to add to potential labor supply. It is also important to know whether those who leave the labor force are likely to be classified as "marginally attached," since the marginally attached are more likely than other labor force nonparticipants to reenter the labor market (see Barnichon and Figura 2013; and Krusell, Mukoyama, Rogerson, and Şahin 2011). ${ }^{15}$

Using linked CPS data, we tabulated responses by those who had been long-term unemployed but then left the labor force to the following question: "(Do/Does) (name/you) currently want a job, either full or part time?" This question is critical for the BLS's classification scheme. Someone who is out of the labor force but indicates that he or she wants a job is asked follow-up questions to determine his or her potential degree of discouragement. Conversely, someone who is out of the labor force but indicates that he or she does not want a job is precluded from being classified as "marginally attached" to the labor force.

Since the Great Recession, fully 73 percent of those who had been longterm unemployed in month 1 and then left the labor force by month 16 indicated that they did not want a job in month 16 of the survey. The share of

14. This conclusion may seem at odds with Davis and von Wachter (2011), who find that earnings losses associated with job displacement are greater if workers are displaced during a period of high unemployment. However, it is unclear to what extent their findings are due to earnings for those who are reemployed versus the chance of becoming reemployed.

15. Currently, the official BLS measures of discouraged workers and marginally attached are relatively low. The U-5 measure of labor underutilization, which includes all marginally attached workers and has as its denominator the civilian labor force plus all persons marginally attached, stood at 8.1 percent in December 2013, just 1.4 percentage point above the headline unemployment rate. 
nonparticipants who report that they do not want a job has trended upward over time (Barnichon and Figura 2013). Nevertheless, the large share of labor force exiters who say they no longer want a job suggests that they are exiting the labor force for an extended period of time. This is consistent with the view that many of the long-term unemployed were induced to search for a job and remained in the labor force longer than they otherwise desired in order to qualify for extended unemployment insurance benefits, and then left the labor force once benefits expired (Rothstein 2011 and Farber and Valletta 2013).

This analysis included all respondents who classified themselves as "long-term unemployed" in their first month of the survey, so it is possible that a substantial portion of these workers may have already been effectively out of the labor force by the time they were surveyed in the CPS in month 16 . To test whether or not this result essentially reflects a misclassification of "long-term unemployed" workers in month 1 of the survey, we also looked at those who reported being long-term unemployed every month during months 1 through 4 and months 13 through 15 and then left the labor force in month 16. Even with this restriction on the consistency of reported long-term unemployment, more than 40 percent of these long-term unemployed workers indicated that they did not want a job in the first month that they left the labor force.

A follow-up question for those who report they do not want a job is, "What best describes (name's/your) situation at this time? For example, (are/is) (you/he/she) disabled, ill, in school, taking care of house or family, or something else?" Typically, those who leave the labor force because they no longer want a job report that they are either "taking care of house or family" or "in school" (Hotchkiss, Pitts, and Rios-Avila 2012).

Since the Great Recession, those who had been long-term unemployed in the initial interview and then left the labor force by month 16 of the survey and reported that they no longer wanted a job indicated that they were currently "taking care of house or family" (51 percent), "in school" (23 percent), or engaged in "other" unspecified activities (20 percent). Other possible responses, including "disability" (4 percent), "illness" ( 2 percent), and "retirement" ( 1 percent), had modest response rates. In comparison to the long-term unemployed, those who had been unemployed for less than 27 weeks in month 1 and then left the labor force by month 16 and reported that they no longer wanted a job were (i) nearly twice as likely to report that they were currently in school (42 percent versus 23 percent), and (ii) less likely to report that they were currently "taking care of house or family" (42 percent versus 51 percent). 
The relatively low rate of long-term unemployed workers who withdraw from the labor force and report a disability suggests that the disability insurance program plays, at most, a minor role in incentivizing the long-term unemployed to withdraw from the labor force or in supporting them once they do withdraw from the labor force. This observation is also consistent with Andreas Mueller, Jesse Rothstein, and Till von Wachter's (2013) conclusion that unemployment insurance exhaustions and disability insurance take-up are unrelated across states.

Lastly, it is worth noting that the behavior of (both short- and long-term) unemployed workers who exit the labor force suggests that those who exit the labor force are likely to do so for an extended period of time. For example, since the beginning of the Great Recession, of those who were long-term unemployed in month 1 and out of the labor force in month 2, 54 percent were out of the labor force and only 25 percent were employed in month 16. For the short-term unemployed, the comparable figures are 49 percent and 33 percent. While the difference in persistence of labor force nonparticipation may not be that great, the short-term unemployed are less likely than the long-term unemployed to exit the labor force in most years (see figures 5 and 11).

\section{Transition Rates: Survey of Income and Program Participation}

The Survey of Income and Program Participation (SIPP) provides an alternative data set with which to examine longer-term transition rates by duration of unemployment. The SIPP has a number of strengths and weaknesses compared with the CPS. Two notable strengths are these: (i) the SIPP is specifically designed to be a longitudinal data set, and individuals who move to a new location are tracked in the survey; (ii) the sample consists of all those who enter a new spell of unemployment within the sample frame, so that unlike the CPS, it does not underrepresent short-term unemployment spells. ${ }^{16}$ In terms of weaknesses, the four-month retrospective interview in each wave of the SIPP has been found to cause "seam" effects that

16. The CPS only includes ongoing spells of unemployment at the time of the survey reference week, which introduces length-biased sampling, and the CPS consequently underrepresents shorter spells of unemployment (Kiefer 1988). If the composition of the flow into unemployment is stable over time, however, the transition rates by duration of unemployment estimated from the CPS are unbiased. In the time period we examine, however, one could question whether the steady-state assumptions apply; hence, the SIPP likely provides a more representative summary of transition rates by duration of unemployment. 
influence transition rates. ${ }^{17}$ In addition, the SIPP cannot be linked every year, lacks information on the duration of unemployment spells that were ongoing at the start of the survey, and has a relatively high attrition and nonresponse rate. Despite these limitations, the SIPP provides a way to assess the robustness of the transition rates estimated from the CPS.

We use data from the 1996, 2001, 2004, and 2008 SIPP panels. ${ }^{18}$ The panels vary in length from 3 years (the 2001 panel) to 5 years (the 2008 panel). We limit our sample to individuals who reported a new spell of unemployment each calendar year, and following Raj Chetty (2008) we exclude the first sample month because new spells cannot be identified that month. The definition of a jobless spell that we employ in the SIPP requires that an individual be newly unemployed; subsequent months are counted in the spell if the individual is either unemployed or out of the labor force. ${ }^{19}$ This categorization differs from the CPS, which asks an unemployed worker to initially report his or her duration of unemployment (which in many cases likely includes months out of the labor force) and then increments the duration by an additional month each subsequent month the worker is without a job, available for work, and actively searching for work.

There are some advantages to using the definition of jobless spells that we apply to the SIPP. For example, a worker who is unemployed for 6 months and then exits the labor force because he becomes discouraged is counted in the CPS as either short-term unemployed, if interviewed in the first 6 months, or as out of the labor force, if interviewed after 6 months,

17. Each SIPP interview covers 4 months. The seam refers to adjacent months that cross from one interview to the next. The monthly transition rate is much higher in months that cross interviews than in months covered by the same interview. For example, in the 2008 panel, the one-month job finding rate was 23 percent between interviews and 9 to 12 percent for months covered by the same interview. The former is close to the CPS figure (which is known to be biased upward because of imperfectly serially correlated classification errors), and the latter could be biased downward because of the tendency for serially correlated classification errors within an interview.

18. The SIPP panels comprise households (and descendant households) that are interviewed at 4-month intervals, called "waves." Each SIPP panel consists of 9 to 15 waves. The sample in each wave consists of four rotation groups, each interviewed in a different month. For example, the first-wave interviews of the 2008 panel occurred from September to December 2008. The reference period for each interview is the preceding 4 months. We do not use data from pre-1996 panels because of significant changes introduced in the 1996 survey.

19. Only the first spell of the year is included for individuals with multiple jobless spells in a calendar year. Across 14 calendar years, there were 24,194 short-term jobless spells (less than 7 months) and 17,272 long-term jobless spells (7 or more months) in our SIPP sample. 
and excluded from our earlier results. Such an individual would be classified as long-term jobless in the SIPP. In any event, the SIPP provides an alternative to the CPS that can be used to probe the robustness of the CPS results, and our attempts to align the SIPP spell definition more closely with the CPS did not meaningfully alter our findings.

Figure 12 shows labor force transition rates for all newly unemployed workers 15 months after entering unemployment, and figure 13 shows the corresponding results for the subset that became long-term jobless (those who were jobless for more than half a year). The contrast between the unconditional and conditional distributions provides an indication of the disparate outcomes between everyone who entered into unemployment and those who became long-term jobless. Paralleling the CPS analysis, the fulltime steady employment category counts workers who were employed fulltime for at least 4 consecutive months. The transition rates are reported according to the year that the jobless spell began. The figures display a pattern that is similar to the one drawn from the CPS. Among all those who became unemployed in 2012, 55 percent were employed 15 months later, and 31 percent of the long-term unemployed were employed. Twenty percent of all newly unemployed workers were in steady full-time positions a year after becoming unemployed in 2012, compared with 12 percent of the long-term jobless.

Nearly half (47 percent) of the long-term jobless were out of the labor force 15 months after entering unemployment in 2012, compared with 29 percent of all unemployed workers. Similar to the pattern in the CPS data, the labor force withdrawal rate for the long-term unemployed has risen over the course of the current recovery. Moreover, although the SIPP data are noisy, the labor force participation rate for the long-term jobless has been higher in expansionary years than in recessionary years, on average, while there is little difference in the participation rate over the business cycle for the newly unemployed.

It is harder to discern cyclical patterns in the SIPP data than in the CPS because some years are missing data, but the job finding rate for the longterm jobless does not appear to be highly cyclical. For the long-term jobless, the average transition rate into either measure of employment was almost identical for those who lost their jobs in the Great Recession years (2008-09) and those who lost their jobs in the last expansion (2004-06). The job finding rates were higher in the late 1990s expansion, but they were about the same for the long-term jobless who entered unemployment during the 2001 recession as for their counterparts who became unemployed during 1996-98. These data do not provide much support for the view that 
Figure 12. Transition Rates for All Jobless Spells, 15 Months after Start of Spell, 1996-2013

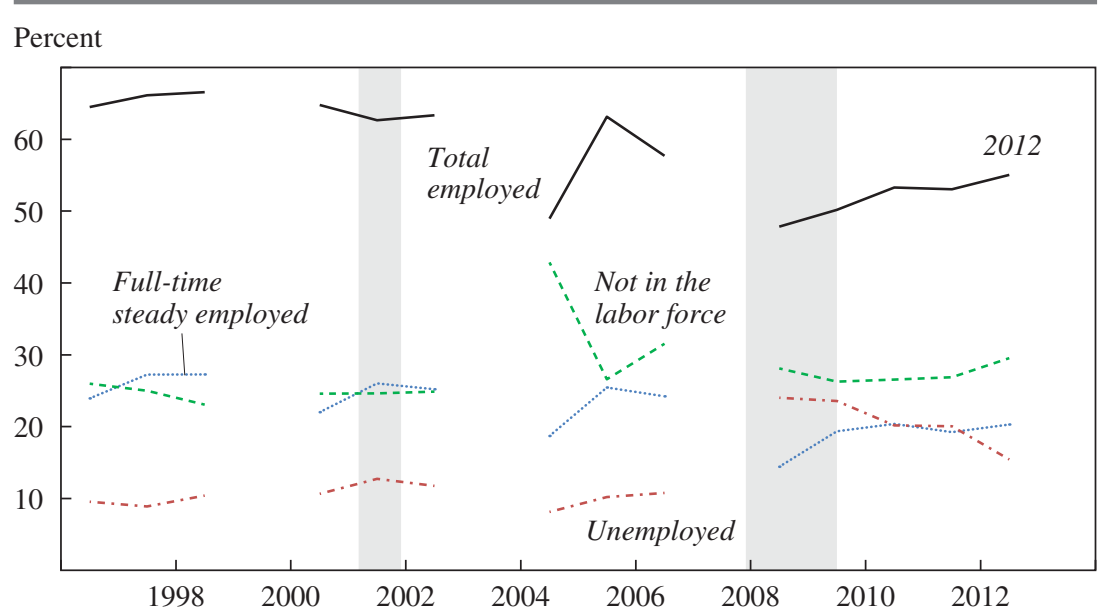

Source: Census Bureau (Survey of Income and Program Participation); National Bureau of Economic Research; authors' calculations.

a. Data cover all workers who became unemployed in the calendar year. Shading denotes recessions.

a stronger macroeconomy has coincided with improved job finding prospects for the long-term jobless.

We performed several checks on the data. First, we limited the sample to those below age 55 to avoid issues of early retirement. Second, we altered the definition of jobless spells by eliminating individuals who did not report searching for a job in at least one subsequent month after becoming unemployed. Third, we defined the duration of a jobless spell by the number of consecutive months an individual searched for a job. Fourth, we excluded individuals who reported that they were on layoff (either temporary or permanent), to preclude the possibility of recall to the workers' previous jobs. In all of these cases, our findings were qualitatively similar to those reported in figures 12 and 13.

\section{IV.A. Longer-Term Transition Rates for Continuous Joblessness}

Thus far in looking at longer-term transitions, we have defined the longterm jobless as all of those who are out of work for more than 6 months. Although this is a common convention in the United States, it is arbitrary. Indeed, we find that there is a more or less continuous relationship between duration of joblessness and hazard rates into employment or out of the labor force. 
Figure 13. Transition Rates for Long-Term Jobless Spells, 15 Months after Start of Spell, 1996-2013a

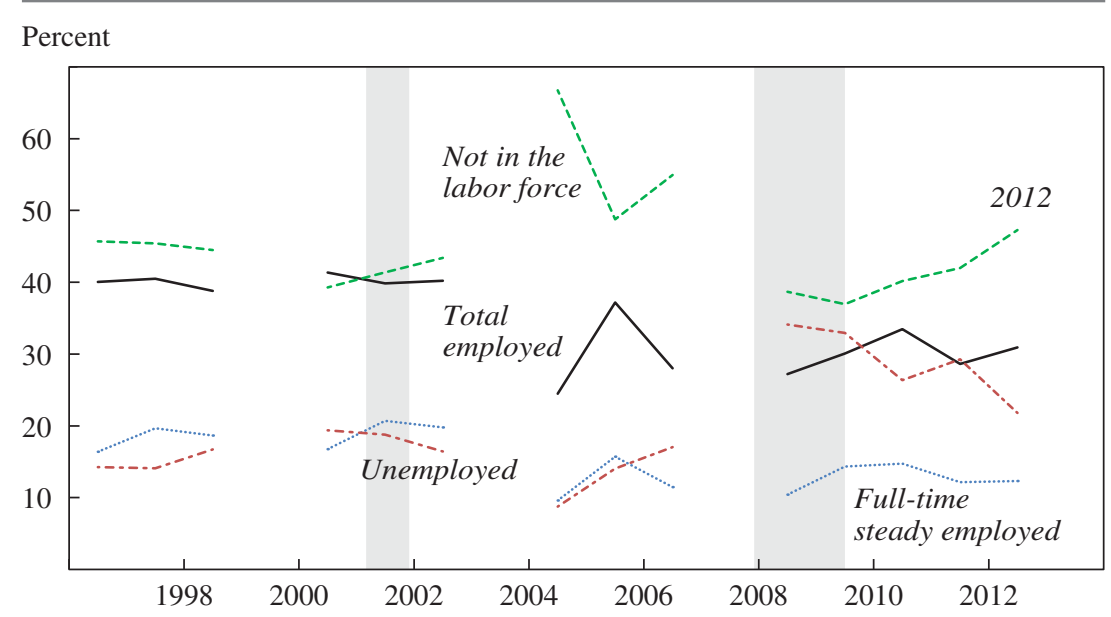

Source: Census Bureau (Survey of Income and Program Participation); National Bureau of Economic Research; authors' calculations.

a. Data cover all workers who became unemployed in the calendar year. Once becoming unemployed, they were jobless, either unemployed or not in the labor force, for at least six consecutive months. Shading denotes recessions.

Figure 14 shows the 15-month-ahead labor force status of workers with various lengths of joblessness, for jobless spells that last from 1 to 36 months, based on the 2008 SIPP panel. The panel began in May 2008 and ended in July 2013, and the sample consists of 18,000 new jobless spells. (An individual could contribute more than one spell if that individual was employed between spells.) Spells are included in the sample until they end in employment or reach 36 months (or are censored). Labor force status is divided into four mutually exclusive groups: full-time steady employed for 4 months in a row as of 15 months later (to match the CPS definition), otherwise employed 15 months later (which includes those employed part-time and others who have not been employed full-time for 4 consecutive months), unemployed 15 months later, and not in the labor force 15 months later.

The results indicate that the likelihood of holding a full-time job for 4 consecutive months a year later (that is, in months 12-15 for someone in the first month of joblessness) tends to decline with the duration of a jobless spell. For example, at the beginning of a spell of unemployment, there was a 19 percent chance of holding a full-time, steady job a year later. 
Figure 14. 15-Month Ahead Transition Rates for All Jobless Spells from 2008 to 2012, by Jobless Spell Duration

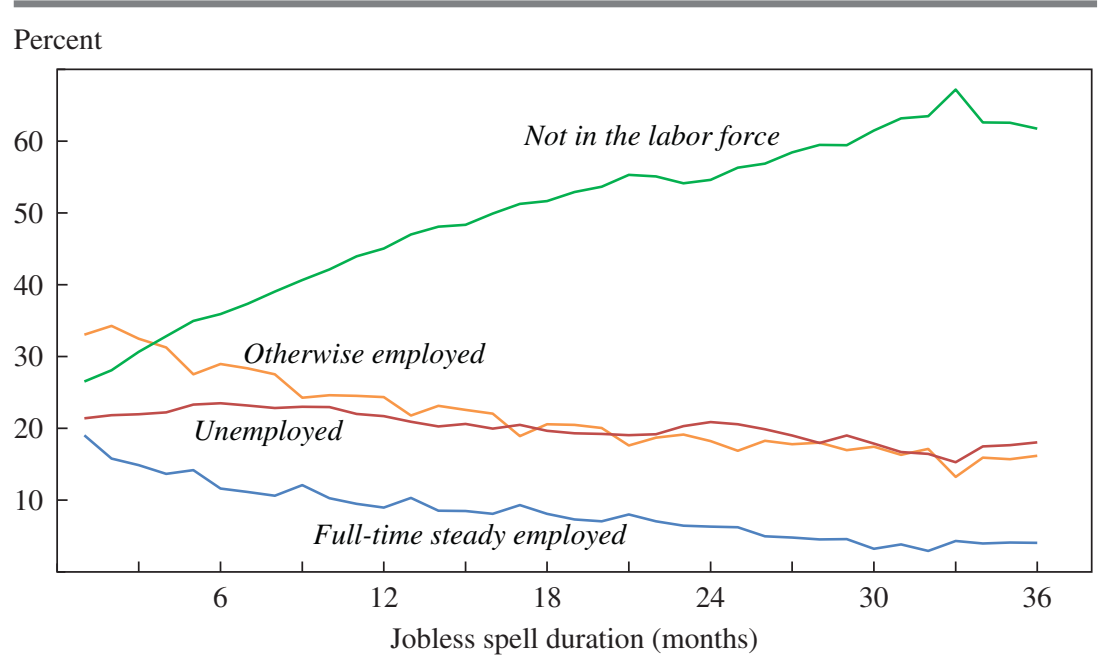

Source: Census Bureau (Survey of Income and Program Participation); authors' calculations. a. Data cover all workers who became unemployed from 2008 to 2012.

For those who were jobless for 6 to 18 months, that probability hovered around 10 percent, and for those who were jobless for 24 months the probability fell to about 6 percent. The probability fell even further, to 4 percent, for those who were jobless for 3 years. The finding that there was only a 19 percent chance of obtaining a full-time, steady job a year after the start of a spell of unemployment reflects the fact that many unemployed workers became long-term unemployed in this period, which was also evident in the CPS comparisons.

The SIPP data also show a declining probability that a jobless worker will hold any job 15 months down the road. A rising share of the jobless tend to leave the labor force as the duration of joblessness increases, while the share unemployed 15 months in the future tends to gradually decline after 6 months of joblessness. These results suggest that assigning the status of long-term unemployed to all those who have been out of work for more than 6 months is an oversimplification that glosses over the poorer prospects of those who have very long jobless spells. Nonetheless, the division does capture substantial differences in the longer-term outcomes between the short- and long-term jobless. It is also a better approximation when it comes to the odds of finding steady, full-time work a year later, given the 
similarity in that transition rate for those out of work for 6 to 18 months, a group that represents a large share of the long-term unemployed.

\section{Transition Rates: Work Trends Survey}

A third data set that we use to examine longer-term transition rates is the Work Trends Survey (WTS), which was conducted by Knowledge Networks for Rutgers University's Heldrich Center for Workforce Development (Zukin, Van Horn, and Stone 2011). The first wave of the WTS was conducted in August 2009. Respondents were asked whether they had been unemployed at any time in the previous 12 months as well as their labor force status at the time of the survey. A total of 1,202 unemployed workers were interviewed and then re-interviewed up to three times, with the final survey taking place in August 2011. The WTS allows for a comparison of ongoing spells and spells that were completed during the year. One weakness in the WTS survey, however, is that individuals who were unemployed in 2009 but out of the labor force as of August 2009 were not asked their duration of unemployment, so they are omitted from our analysis. The WTS data are also likely to suffer from other measurement problems, such as errors in respondents' recall of their unemployment duration during the initial survey, but they nonetheless provide an alternative vantage point for viewing the 2-year labor force transition rates for those who were unemployed in the 12 months ending in August 2009.

Table 3 reports a tabulation of the WTS data. The combined sample of ongoing and completed spells indicates that 63 percent of those who were (or had been) short-term unemployed in the 12 months ending in August 2009 were employed in August 2011, compared with 47 percent of those who were (or had been) long-term unemployed in the 12 months ending 2009. The survey has information on full-time status as of August 2011, and the percentage-point gap is just as large: 38 percent versus 22 percent. The long-term unemployed were a bit more likely to have left the labor force, but the labor force participation rate in the WTS data is considerably higher than in the CPS or SIPP, probably because those who had withdrawn from the labor force by August 2009 were necessarily excluded from the sample. In view of the fact that the transition rate is over a period of 2 years as opposed to 15 months, the job finding results are generally consistent with the CPS and SIPP data. Nevertheless, the stronger attachment to the labor force exhibited by both the short-term and long-term unemployed in the WTS data is surprising. 
Table 3. Long-Term Labor Force Transitions from Work Trends Survey ${ }^{a}$ (percent)

Short-term unemployed

Sample: ${ }^{\mathrm{C}}$

Labor force status 2 years later

\begin{tabular}{ccc}
\hline Ongoing spells $^{\mathrm{c}}$ & Completed spells $^{\mathrm{d}}$ & Combined \\
\hline 52.7 & 83.5 & 63.1 \\
23.7 & 67.3 & 38.4 \\
15.6 & 8.1 & 13.1 \\
31.8 & 8.4 & 23.9 \\
175 & 82 & \\
\hline
\end{tabular}

Long-term unemployed ${ }^{\mathrm{b}}$

Sample: ${ }^{\mathrm{c}}$

\begin{tabular}{lccc}
\cline { 2 - 4 } Labor force status 2 years later & Ongoing spells $^{\mathrm{c}}$ & Completed spells $^{\mathrm{d}}$ & Combined $^{\text {Engloyed }}$ \\
\hline Employed full-time & 42.4 & 84.5 & 47.7 \\
Employe & 15.8 & 67.4 & 22.3 \\
Not in the labor force & 15.8 & 3.3 & 14.2 \\
Unemployed & 41.8 & 12.2 & 38.1 \\
$N$ & 284 & 30 &
\end{tabular}

Source: Heldrich Center's Work Trends Survey, Roper Center; authors' calculations.

a. Sample of those who were unemployed at some point between August 2008 and August 2009. Results use sample weights from first wave.

b. Long-term were either unemployed for more than six months in August 2009 or had been unemployed for more than six months in the previous year before gaining employment.

c. Refers to those out of work at the time of initial survey.

d. Refers to those who were employed by the time of the initial survey.

As one would expect, completed spells represent a larger share of all spells for the short-term unemployed (32 percent) than for the long-term unemployed (10 percent). The distribution of labor force status 2 years after the August 2009 survey is much more similar between the short-term and long-term unemployed for those who had completed their spell of unemployment as of the initial survey than it is for those who were in ongoing spells at that time. Comparing the ongoing spells with the combined sample, the gap in employment between the short-term and long-term unemployed is larger in the combined sample (using either measure of employment). There are many possible sources of these differences between the ongoing and combined sample. For example, the spells in the combined sample started a bit earlier in calendar time than the spells in the completed sample, and the composition of the newly unemployed could have changed over 2008-09. In any case, the estimates point to a 20-25 percent lower job finding rate for the long-term unemployed than the short-term unemployed, and a 33-42 percent lower rate for full-time jobs. These rates encompass the range of 
Table 4. Long-Term Labor Force Transitions from Work Trends Survey, Excluding Recall ${ }^{a}$ (percent)

\begin{tabular}{|c|c|c|c|}
\hline \multirow[b]{2}{*}{ Labor force status 2 years later } & \multicolumn{3}{|c|}{ Sample: } \\
\hline & Ongoing spells & Completed spells & Combined \\
\hline Employed & 50.7 & 87.2 & 63.8 \\
\hline Employed full-time & 27.3 & 71.4 & 43.3 \\
\hline Not in the labor force & 15.6 & 3.4 & 12.6 \\
\hline Unemployed & 33.7 & 9.4 & 23.6 \\
\hline$N$ & 142 & 54 & \\
\hline
\end{tabular}

Long-term unemployed

\begin{tabular}{lccc} 
& \multicolumn{3}{c}{ Sample: } \\
\cline { 2 - 4 } Labor force status 2 years later & Ongoing spells & Completed spells & Combined \\
\hline Employed & 41.2 & 88.1 & 47.0 \\
Employed full-time & 16.4 & 61.4 & 23.3 \\
Not in the labor force & 16.4 & 7.5 & 14.6 \\
Unemployed & 42.5 & 4.4 & 38.4 \\
$N$ & 259 & 23 &
\end{tabular}

Source: Heldrich Center's Work Trends Survey, Roper Center; authors' calculations.

a. Excludes workers who reported that there is "a good chance" or "some chance" they could work for their former employer. See table 3 notes for additional details.

estimates from the CPS and SIPP, despite the surveys' varying designs, definitions of unemployment, and spans of time between surveys.

Lastly, the WTS data can be used to exclude individuals who expected to be recalled to their previous job in August 2009 (table 4). Sixteen percent of the unemployed workers surveyed in 2009 reported that they had a "good chance" or "some chance" that they could return to their former employer. If we drop these individuals from the sample, the pattern of transition rates by duration of unemployment is notably similar. For example, in the combined sample, 43 percent of the short-term unemployed were in full-time jobs 2 years later, compared with 23 percent of the long-term unemployed. This suggests that the possibility of recall does not account for the difference in reemployment rates between the short-term and long-term unemployed in this sample.

\section{Regional Differences within the United States}

Some states are further along than others in recovering from the Great Recession. As of 2013, 11 states had unemployment rates that were below their average over the 25 years before the Great Recession (from 1982 to 
Figure 15. Long-Term Unemployed Share by Whether State Is above or below Long-Run Unemployment Average, 1982-2013

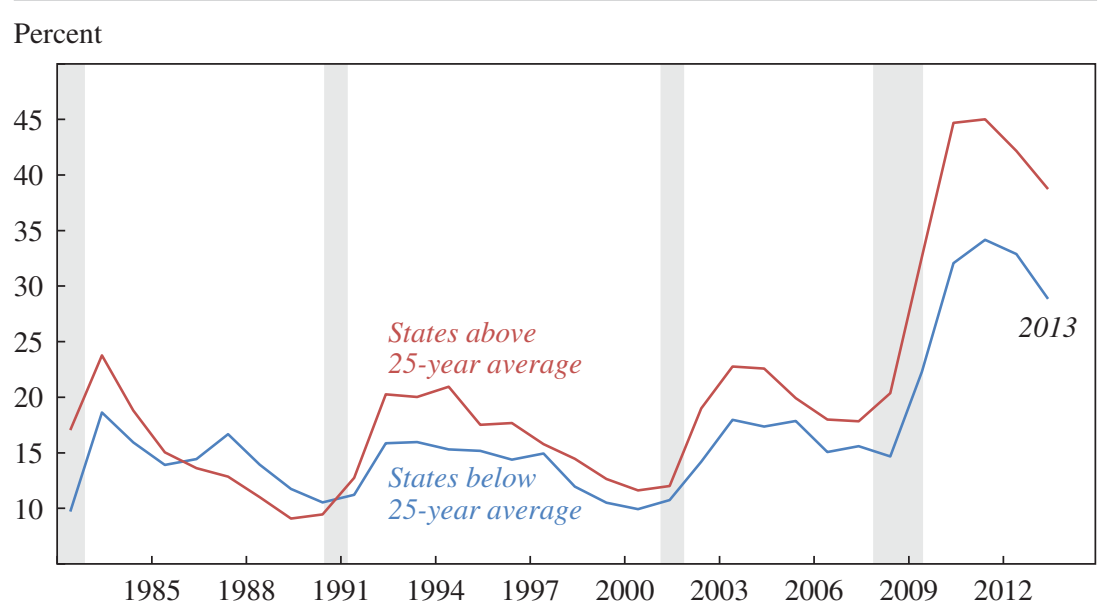

Source: Authors' calculations using Current Population Survey Longitudinal Population Database (see Nekarda 2009); National Bureau of Economic Research; Bureau of Labor Statistics.

a. Shading denotes recessions.

2007). These states provide a possible indication of how the long-term unemployed could fare in a stronger economy. Our analysis suggests that long-term unemployment remains an unprecedented problem even in states that are currently experiencing low unemployment compared to their historical norm. The low-unemployment-rate states, many of which have benefited from a boom in energy production, are Alaska, Iowa, Louisiana, Montana, North Dakota, Oklahoma, Texas, Utah, Vermont, West Virginia, and Wyoming. The average unemployment rate in these 11 states in 2013 was 5.2 percent, compared with 7.2 percent in the rest of the country.

The shares of long-term unemployment in the two sets of states are shown in figure 15, based on tabulations of the CPS each year from 1982 to 2013. The states with 2013 unemployment rates below their 25-year average also had relatively low unemployment and low long-term unemployment shortly before the Great Recession. Long-term unemployment grew dramatically in the low-unemployment-rate states during the Great Recession, reaching almost 35 percent of total unemployment in 2011, well above prerecession levels; for comparison, the previous high nationwide was 26 percent. The states with higher unemployment rates had a peak long-term-unemployment share of 45 percent, but the rise in 
long-term unemployment in these states started from a higher base. The long-term unemployment shares have fallen at about the same pace in both sets of states, down 6 percentage points from their peak in both groups. Even in states where the unemployment rate had fallen below its historical average, however, in 2013 the share of long-term unemployed workers exceeded the previous nationwide peak.

To compare the longer-term prospects of the unemployed in both groups of states, we next examine long-term transition rates by duration of unemployment, using matched CPS data. The six panels in figure 16 show the transition rates of the unemployed into: (upper panels) any employment 15 months later; (middle panels) full-time, steady employment starting a year later; and (lower panels) being out of the labor force 15 months later. The left-hand graph of each panel displays results for the short-term unemployed and the right-hand graph for the long-term unemployed. The figures do not show much evidence that the long-term unemployed are faring notably better in transitioning to employment in the low-unemployment states than they are in the high-unemployment states.

In the last year (2013), however, there has been an encouraging sign that the long-term unemployed are more likely to transition to full-time, steady positions in the low-unemployment states. It will be important to monitor whether this spike in transitions into steady employment continues. (It is also worth noting that despite this spike, 85 percent of the long-term unemployed in the low-unemployment states still had not managed to find steady, full-time employment a year after being initially surveyed.) The short-term unemployed, by contrast, have shown more consistent signs of improved job finding outcomes in the low-unemployment states since the start of the recovery. That pattern is consistent with the nationwide time-series evidence in table 2, which shows a stronger response to economic conditions by the short-term unemployed than by the long-term unemployed.

The two lower graphs in figure 16 show that labor-force exit rates have been roughly comparable in both sets of states, especially for the shortterm unemployed in the postrecession period. The labor force withdrawal rate for the long-term unemployed during the recovery has been slightly higher in the low-unemployment states than in the high-unemployment states, highlighting the risk that the long-term unemployment rate may return to normal because many of the long-term unemployed eventually exit the labor force. This issue is explored further in the calibration exercise in the next section. 
Figure 16. Long-Term Labor Force Transitions, by Status of 2013 State Unemployment Rate above/below Historical Average, 1994-2012

Transition to employment after 15 months

\section{Short-term unemployed}

Percent of total labor force status flows

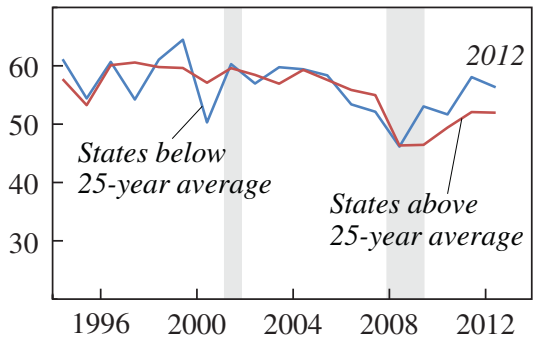

Long-term unemployed

Percent of total labor force status flows

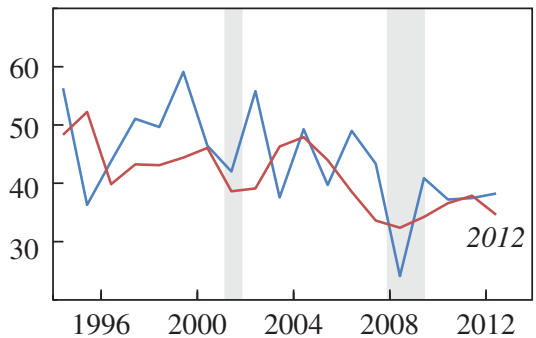

Transition to full-time, steady employment after 15 months

Short-term unemployed

Percent of total labor force status flows

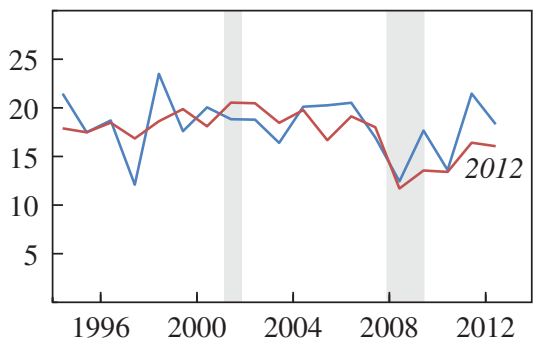

Long-term unemployed

Percent of total labor force status flows

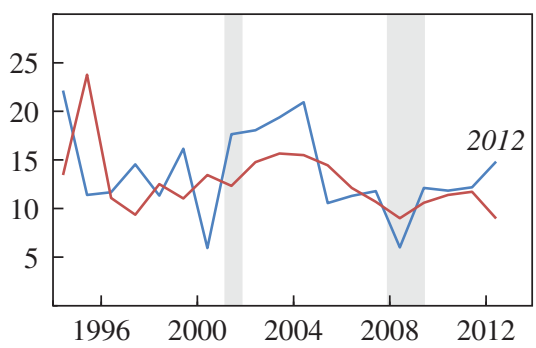

Transition to out of the labor force after 15 months

Short-term unemployed

Percent of total labor force status flows

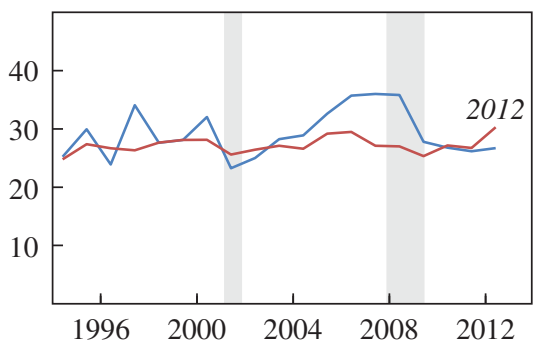

Long-term unemployed

Percent of total labor force status flows

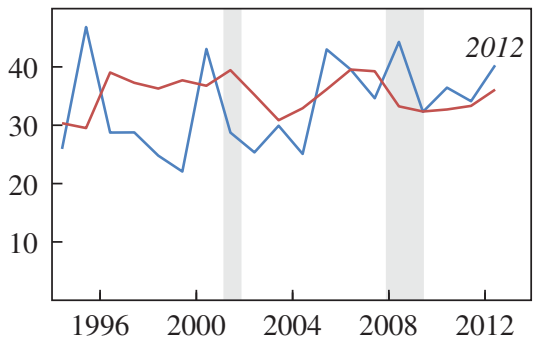

Source: Authors' calculations using Current Population Survey Longitudinal Population Database (see Nekarda 2009); National Bureau of Economic Research.

a. Shading denotes recessions. Year on $x$-axis represents the survey entry year. Long-term unemployed defined as unemployment duration greater than 26 weeks. 
Figure 17. Job Vacancy Rate vs. Unemployment Rate, 2000-14a

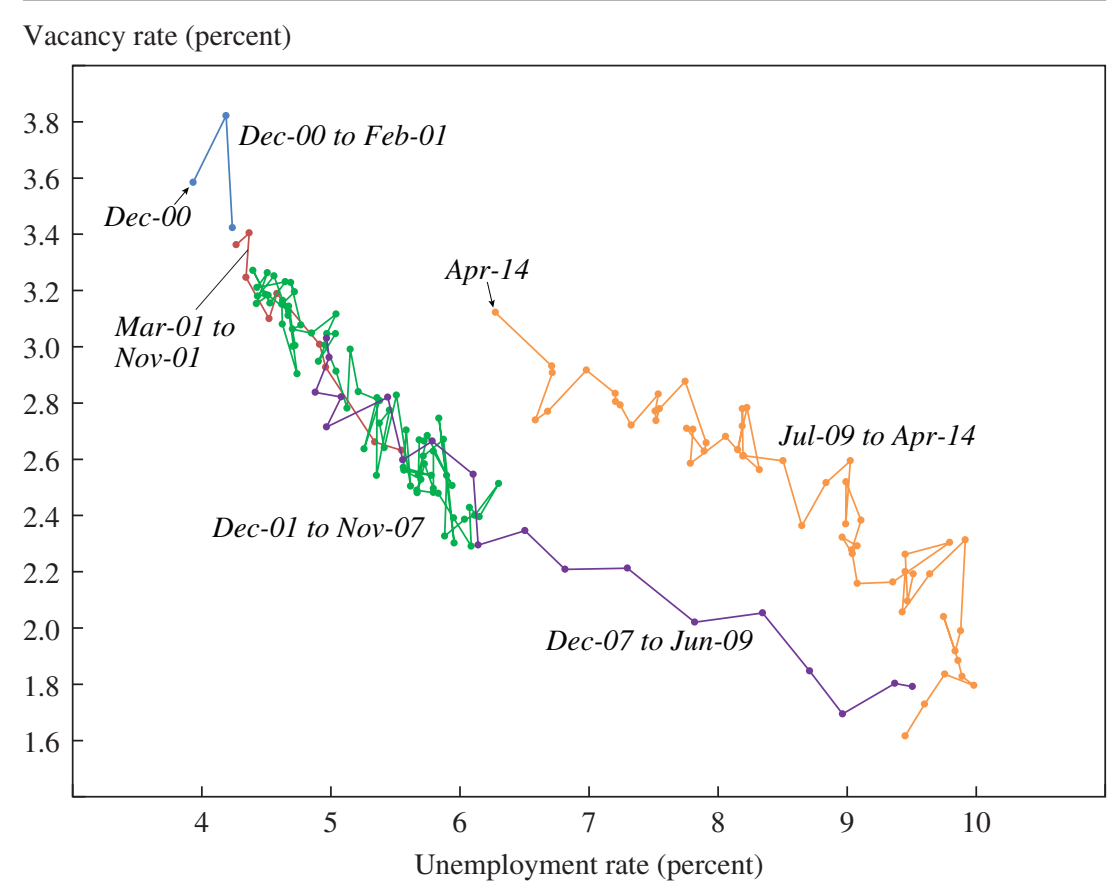

Source: Bureau of Labor Statistics (Job Openings and Labor Turnover Survey, Current Employment Statistics, and Current Population Survey).

a. Job vacancy rate is defined as job openings as a percentage of the sum of job openings and total nonfarm payroll employment.

\section{Calibration Model}

As is well known, after the Great Recession the relationship between vacancies and the unemployment rate, known as the Beveridge curve, shifted outward, with more vacancies than predicted given the high unemployment rate. ${ }^{20}$ Figure 17 shows the Beveridge curve using the total unemployment rate, and figure 18 shows that this relationship is stable using the shortterm unemployment rate. One possibility is that, after a severe shock, the Beveridge curve shifts out because of slow job growth, a rise in long-term unemployment, a reduction in overall match efficiency, and a decline in labor force exits, particularly among the long-term unemployed. The path of unemployment and vacancies could eventually loop back to the original Beveridge curve position because many of the long-term unemployed

20. See Hobijn and Şahin (2012) for international evidence. 
Figure 18. Job Vacancy Rate vs. Short-Term Unemployment Rate, 2000-14

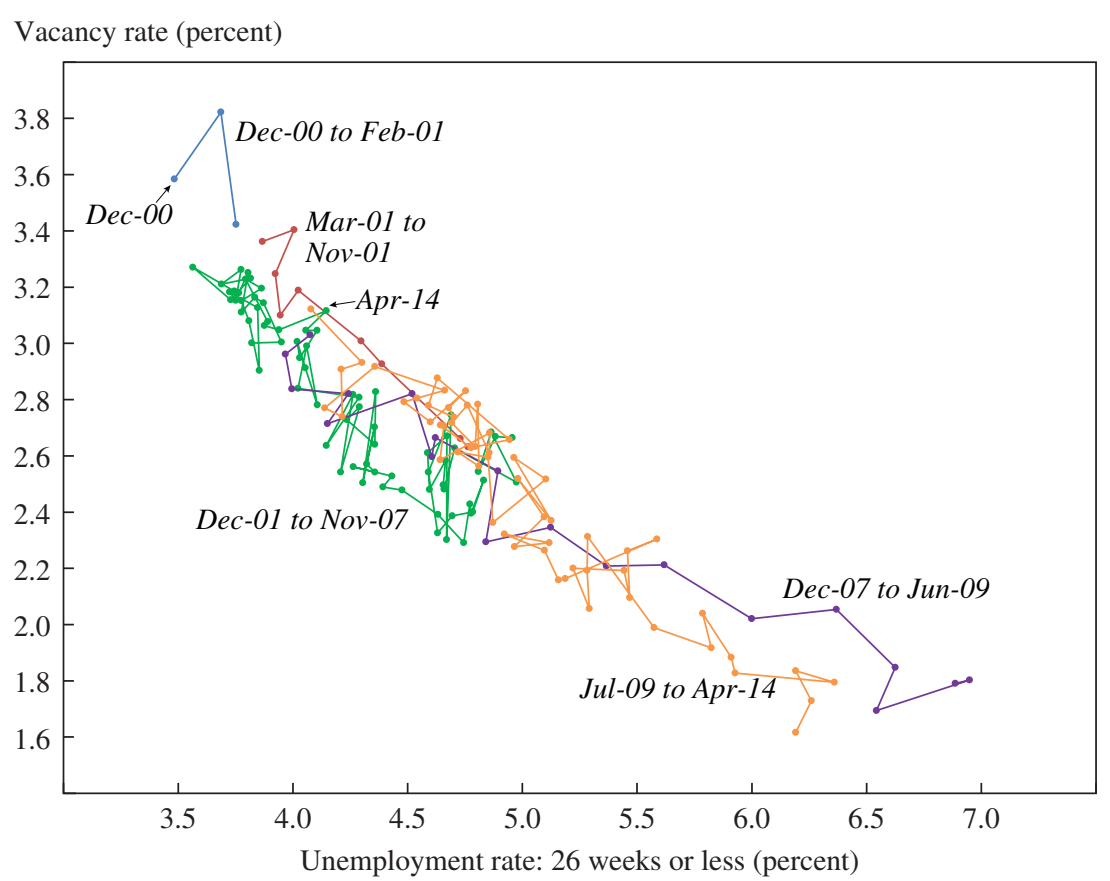

Source: Bureau of Labor Statistics (Job Openings and Labor Turnover Survey, Current Employment Statistics, and Current Population Survey).

a. See figure 17 notes for details.

exit the labor force or (less likely) find a job, and the unemployment rate reflects a lower share of long-term unemployed workers after a time. ${ }^{21}$ Our goal in this section is to explore these hypotheses with a calibrated model of labor force flows and job matching in which the labor force withdrawal rate by duration eventually moves back to its historical norm.

Specifically, we extend the calibration model in Kroft and others (2014). Kroft and colleagues estimate a search and matching model that is a simplification of Dale Mortensen and Christopher Pissarides (1994) and Robert Shimer (2005), with slight adjustments to help fit the data (for example to adjust for population growth and inconsistencies in flow data and reported durations). They focus on workers age 25 to 54 to avoid issues concerning the aging of the baby boom and increased school attendance. The authors

21. See Blanchard and Diamond (1989 and 1994) for a prescient discussion of loops around the Beveridge curve and a model based on the assumption that employers rank job applicants based on their duration of unemployment. 
assume that the unemployed $(U)$ and nonparticipants $(N)$ "meet" job openings according to a Cobb-Douglas "meeting function":

$$
M(U+s N, V)=m_{0}(U+s N)^{\alpha} V^{1-\alpha},
$$

where $M$ are meetings, $s$ is the weight on the meeting efficiency of those not in the labor force relative to the unemployed, and $V$ are vacancies. The authors assume that the share of meetings that go to the unemployed equals their share of search-intensity weighted nonemployment: $\frac{U}{U+s N}$. The remaining meetings go to those not in the labor force, who are assumed to be hired if they obtain a meeting. The authors further assume that the probability that a meeting results in a hire for an unemployed individual is a declining function of his or her duration of unemployment, $A(d)$, where $d$ is duration. The authors then estimate $\alpha$ and $s$ to minimize the distance between the actual job finding rates for the unemployed and those not in the labor force between 2002 and 2007, and the predicted flows from the model:

Probability of moving from unemployment to employment $=A(d) m_{0} x_{t}^{1-\alpha}$.

Probability of moving from out of the labor force to employment $=$ $s m_{0} x_{t}^{1-\alpha}$ where $x_{t}=\frac{V_{t}}{U_{t}+s N_{t}}$ and $m_{0}$ is a constant.

Using the predicted job finding rates for the unemployed by duration and those not in the labor force, as well as actual transition rates into nonemployment and the actual path of vacancies, Kroft and others (2014) are able to capture most of the rise in the share of long-term unemployed workers as a result of the slowdown in job vacancies that accompanied the Great Recession, as opposed to a change in the labor market performance of the long-term unemployed relative to the short-term unemployed. However, their model generates only a modest loop around the Beveridge curve that quickly returns to the original position. ${ }^{22}$

22. This observation is based on our replication of their model. In particular, when we replicated their model we also found a rise in the share of the long-term unemployed that mirrored the observed data. When we projected the Beveridge curve using their model, there was only a slight outward shift in the curve after the Great Recession that returned to the original position by late 2012, whereas the actual unemployment rate has not returned to the original curve as of this writing (June 2014). Intuitively, this finding resulted because their meeting function generated job growth, and a consequent drop in unemployment, that was stronger than observed in the recovery because it did not allow for a lower meeting rate of the long-term unemployed. 
We extend their model in two important respects. First, using data from 2002-07, we estimate a job matching function, rather than a meeting function, of the form:

$$
J=\left(U_{S}+\delta U_{L}+\xi N\right)^{\alpha}(V)^{1-\alpha},
$$

where $J$ is the number of jobs being filled by the nonemployed, $U_{S}$ is the number of short-term unemployed workers, $U_{L}$ is the number of longterm unemployed workers, $N$ is the number of nonparticipants, and $V$ is the number of vacancies. The parameters $\delta$ and $\xi$ reflect the potentially lower match efficiency of the long-term unemployed and nonparticipants. The short-term unemployed are defined as those with less than 27 weeks of unemployment, while the long-term unemployed are those with 27 weeks or more of unemployment. We estimate the parameters of the matching function by minimizing the distance between the system of equations for flows into employment for nonparticipants, short-term unemployed, and long-term unemployed using monthly CPS data. ${ }^{23}$ The estimated coefficients (with bootstrapped standard errors in parentheses) are: $\delta=0.60(.03), \xi=0.29$ (.01), and $\alpha$ is $0.79(.06)$. Kroft and others (2014) implicitly assumed that $\delta=1$ in their meeting function, although they allowed for differential job finding rates for the short- and longterm unemployed because their meeting function is combined with $A(d)$ terms to generate job matches. Their estimate of $s$ was close to our estimate of $\xi$.

Kroft and others (2014) imposed the same labor force withdrawal rate for the short-term and long-term unemployed. While this was plausible in the immediate aftermath of a recession, over time the labor force withdrawal rate tends to rise as the economy recovers, especially for the longterm unemployed (see figure 5). Our second extension is that we allow for differential labor force withdrawal rates by duration of unemployment.

We follow Kroft and others (2014) in letting the observed number of vacancies, labor force withdrawal rates, and transitions into unemployment evolve as they did from January 2008 forward. We also follow Kroft and others and assign a duration of unemployment to those who initially transition from nonparticipant to unemployed, and those who transitioned from employed to unemployed, based on the observed distributions in that

23. To be more precise, the parameters were estimated using the labor force flows for those with more or less than 26 weeks of unemployment, and ensuring that the stocks of the number of unemployed workers implied by the transition rates match the actual CPS stocks of those with 6 and 7 months of unemployment. 
Figure 19. Calibrated Beveridge Curve, Actual vs. Simulated, 2000-13a

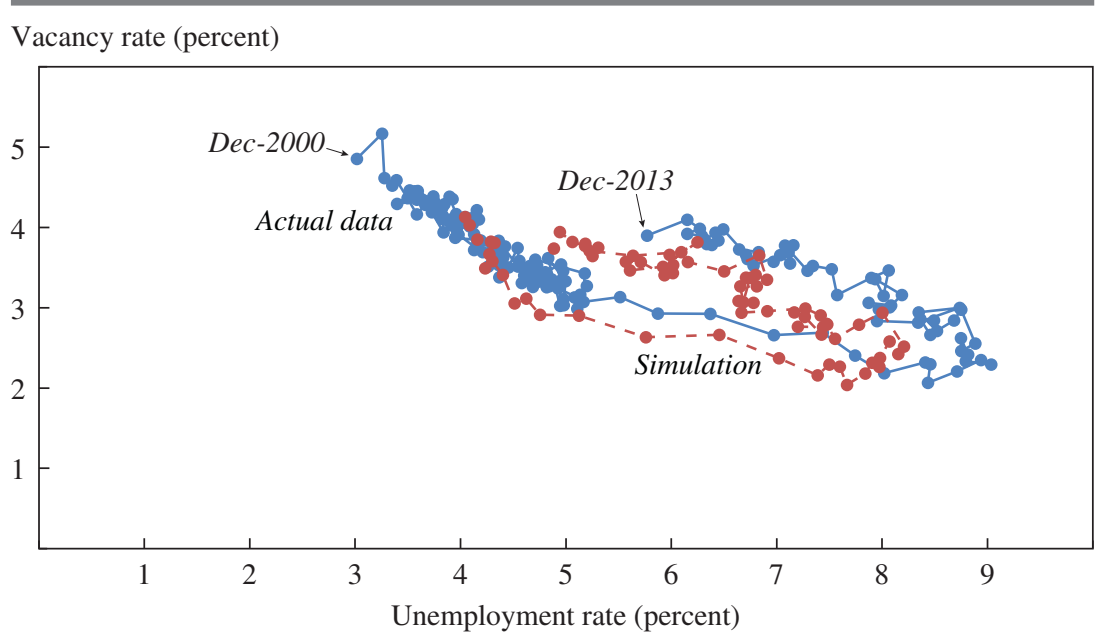

Source: Bureau of Labor Statistics (Current Population Survey and Job Openings and Labor Turnover Survey); authors' calculations.

a. Both vacancy and unemployment rates are percentages of the labor force ages 25 to 54 .

calendar year. For those who remain unemployed from one period to the next, we increment their duration of unemployment by 1 month.

Figure 19 uses our matching function estimated over the period 2002-07 to project the Beveridge curve from 2008 to 2013. The projection seems to match the broader trends in the data reasonably well. The calibrated model predicts an outward shift in the Beveridge curve similar to what has been observed. In 2012 and 2013, the projection begins to move back toward the original Beveridge curve. The projection initially underpredicts the 5-percentage-point rise in the unemployment rate from January 2008 to October 2009 by one percentage point, and remains slightly to the left of the actual data. This under-prediction is consistent with Robert Hall and Sam Schulhofer-Wohl (2013), who find that there has been a steady downward drift in matching efficiency in the 2000s. ${ }^{24}$ As the labor force exit rate of both the long- and short-term unemployed began to rise, the projection began to move closer to the original Beveridge curve. As of December 2013, the model predicts that the unemployment rate would be 0.8 percentage point lower than the actual rate. As a whole, however, the calibrated model seems to capture the broad outlines of the shift of the

24. Hall and Schulhofer-Wohl's analysis focuses on eight different types of job seekers to control for heterogeneity. 
Figure 20. Calibrated Beveridge Curve with 2006-07 Average Labor Force Exit Rates, $2000-13^{a}$

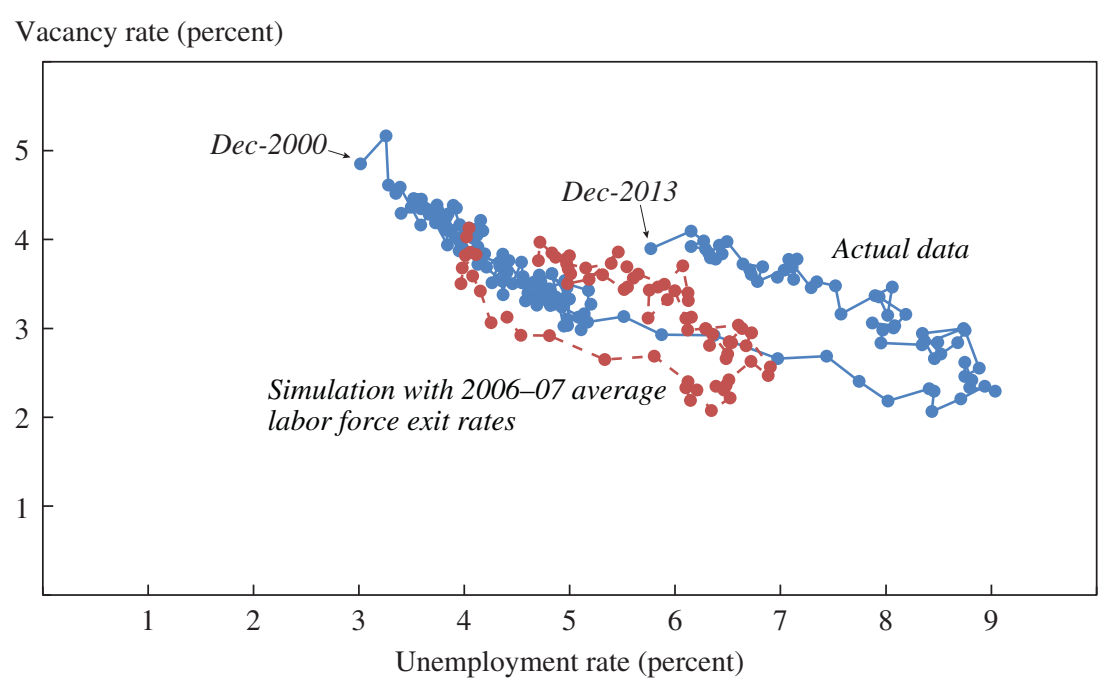

Source: Bureau of Labor Statistics (Current Population Survey and Job Openings and Labor Turnover Survey); authors' calculations.

a. Both vacancy and unemployment rates are percentages of labor force ages 25 to 54 .

Beveridge curve reasonably well. The root mean square error between the actual unemployment rate and projection based on the calibrated model is 0.9 percentage point.

We next use the calibrated model to investigate the impact on unemployment of the cyclical path of labor force withdrawals by duration of unemployment. As mentioned earlier, labor force exits collapsed for the long-term unemployed during the Great Recession and in the ensuing few years, before rising in the direction of their historical average. What impact did this pattern have on the unemployment rate and shift in the Beveridge curve? Figure 20 presents calibrated results where we impose the labor-force withdrawal rates for the long-term and short-term unemployed that occurred in 2006-07, just before the recession, each year going forward. Had labor force withdrawal rates not collapsed and instead remained at their 2006-07 levels, the figure indicates that the loop around the Beveridge curve would have been much more circumscribed and short-lived. The unemployment rate would have been underpredicted by 3 percentage points under this scenario. The root mean squared error in this counterfactual model rises to 1.6 percentage points, substantially worse than the fit when the actual path of labor force participation by duration of unemployment is used in the model. 
To explore the role of the gradual increase in labor force withdrawal by the unemployed since the unemployment rate peaked in October 2009, we conducted another counterfactual exercise, in which we maintained the labor force withdrawal rates for the short-term and long-term unemployed at their October 2009 levels and projected the unemployment rate through December 2013 using the estimated matching function and all of the other realized flow data. Compared to the calibrated model (with the same matching function and realized flow variables, including actual labor force withdrawal rates) the unemployment rate was 1.3 percentage points higher in the counterfactual projection. Thus, the increase in labor force withdrawal rates from October 2009 through December 2013 appears to account for a little over one percentage point of the 3.2-percentage-point drop in the unemployment rate for prime-age workers. In this period, the labor force withdrawal rate for the short-term unemployed had returned to close to its historical average, while the rate for the long-term unemployed was still below it.

To probe what the calibration exercise implies going forward, we extended the projections through 2016 starting with the data observed for December 2013. Vacancies are treated as exogenous in the model; we assumed that vacancies grow at the same rate as they have over the last 2 years (31,000 per month). The labor force exit rates of the long- and shortterm unemployed are assumed to linearly return from their December 2013 levels to their 2006 averages by 2016, an assumption that appears consistent with the 2002-07 recovery and current trends (see figure 5), as are the other flows to nonemployment. Under these assumptions, figure 21 shows that by December 2016 the labor market is projected to almost return to the original Beveridge curve. This implies that the combination of rising labor force withdrawal rates and lower match efficiency for the long-term unemployed can account for a loop around the Beveridge curve.

Lastly, figure 22 shows the share of prime-aged workers who are predicted by the model to be long-term unemployed each month since December 2007. The matching function does a relatively good job of capturing the rise in the share of long-term unemployment from 2009 to $2010 .{ }^{25}$ An extension of the calibrated model implies that as vacancies and matches rise, coupled with labor force withdrawal rates returning to their earlier, higher levels, long-term unemployment is expected to decline gradually, although by the end of 2016 its share is projected to remain well above prerecession levels.

25. The increases in the share of long-term unemployed at the beginning of 2011 and 2012 are due to a feature of the calibration model: at the beginning of the year, the distribution of unemployment spells for those who entered unemployment from employment or out of the labor force is updated to correspond to the actual distribution for such workers in that calendar year. 
Figure 21. Forecast of Beveridge Curve if Labor Force Outflows Return to 2006 Level, 2000-12 and 2013-16 (Projected) ${ }^{\mathrm{a}}$

Vacancy rate (percent)

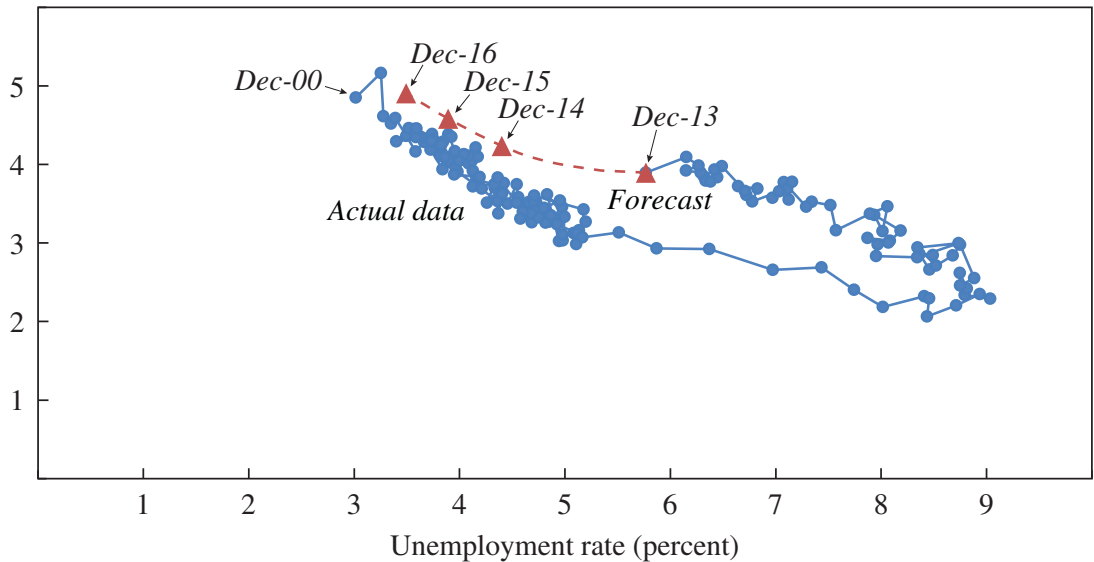

Source: Bureau of Labor Statistics (Current Population Survey and Job Openings and Labor Turnover Survey); authors' calculations.

a. Vacancy and unemployment rates are percentages of labor force ages 25 to 54 .

Figure 22. Long-Term Share of Unemployment from Calibration, 2007-12 and 2013-16 (Projected) ${ }^{\mathrm{a}}$

Percent of unemployed ages 25-54

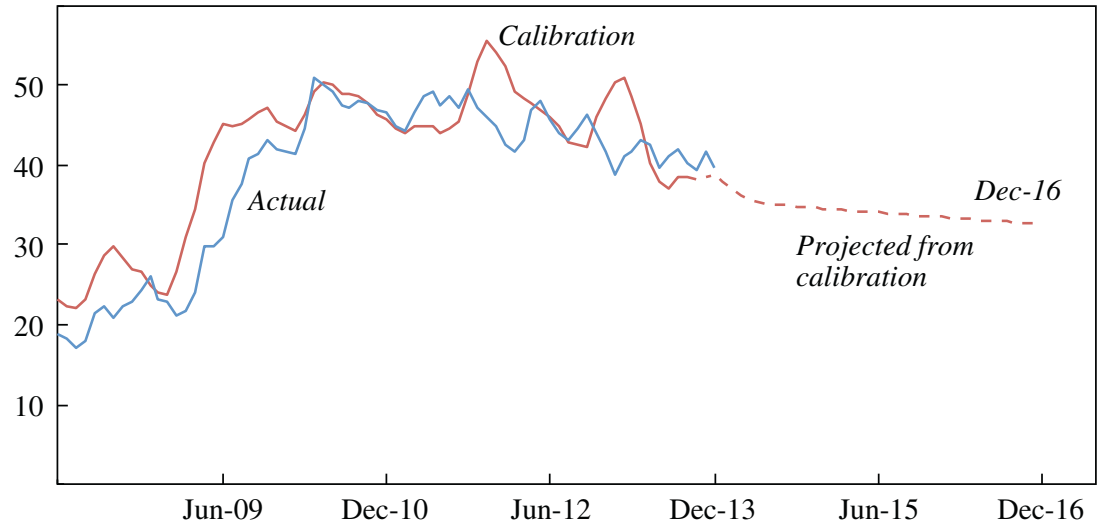

Source: Bureau of Labor Statistics (Current Population Survey and Job Openings and Labor Turnover Survey); authors' calculations.

a. Long-term unemployment is defined as greater than 26 weeks. 
We conclude from this exercise that the varying pattern of labor force withdrawal by unemployment duration is an important feature of the job market. Moreover, the fact that a similar pattern was observed in the past recovery suggests that labor force withdrawal of the long-term unemployment rate is historically an important (but unfortunate) mechanism by which the labor market returns to equilibrium.

\section{Conclusion}

The Great Recession and subsequent recovery have been distinguished by an exceptionally high rate of long-term unemployment. The extent to which the long-term unemployed actively search for a job and transition into employment or grow discouraged and exit the labor force will determine the degree of effective slack in the economy. Across a variety of data sets, over a horizon of 1 to 2 years the job finding rate among the long-term unemployed is about 20 to 40 percent below that of the short-term unemployed. Although the long-term unemployed have about a 1 in 10 chance of moving into employment in any given month, when they do return to work their new jobs are often transitory. After 15 months, the long-term unemployed are more than twice as likely to have withdrawn from the labor force as to have settled into steady, full-time employment. And when they do exit the labor force, the unemployed tend to say that they no longer want a job, suggesting that many labor force exits could be enduring. Furthermore, our calibration exercise suggests that the decline and gradual rise in labor force exits of the long-term unemployed over the business cycle plays an important role in the outward and then inward shift of the unemployment-vacancy relationship.

Past research has found many benefits of a high-pressure labor market, such as wage growth and upward career mobility, but many of those benefits do not appear to accrue to the long-term unemployed. ${ }^{26}$ Job finding rates are more sensitive to the state of the business cycle for the shortterm unemployed than they are for the long-term unemployed, suggesting that the long-term unemployed are more insulated from macroeconomic developments than the short-term unemployed. Labor force exit rates are countercyclical for the long-term unemployed. Even in the roaring 1990s, a relatively small share of the long-term unemployed returned to full-time, stable employment; their problems were less prominent then because they accounted for a smaller share of the unemployed, however. Indeed, the main benefit of a stronger economy in regard to long-term unemployment

26. See Okun (1973) and Katz and Krueger (1999). 
may be that it reduces the likelihood that the short-term unemployed become long-term unemployed.

The portrait of the long-term unemployed in the United States that emerges here suggests that, to a considerable extent, they are an unlucky subset of the unemployed, and that their prospects decline the longer they remain unemployed, possibly because their skills atrophy. Their diverse and varied set of characteristics implies that a broad array of policies will be needed to substantially raise their job finding rate and stem their rising labor force withdrawal rate, since concentrating on any single occupation, industry, demographic group, or region is unlikely to materially improve the well-being of the long-term unemployed by itself. Understanding both the labor market hurdles and the personal hurdles faced by the long-term unemployed should be a priority for future research in order to craft solutions to reduce long-term unemployment.

Some may wish to draw macroeconomic policy implications from our findings. Only time will tell if inflation and real wage growth are more dependent on the short-term unemployment rate than on the total unemployment rate. To us, the most important policy challenges involve designing effective interventions to prevent the long-term unemployed from receding into the margins of the labor market or withdrawing from the labor force altogether, and supporting those who have left the labor force to engage in productive activities. Overcoming the obstacles that prevent many of the long-term unemployed from finding gainful employment, even in good times, will likely require a concerted effort by policymakers, social organizations, communities, and families, in addition to appropriate monetary policy.

ACKNOWLEDGMENTS We thank Katharine Abraham, Peter Diamond, Hank Farber, Bo Honoré, Larry Katz, Scott Kostyshak, Chris Nekarda, Richard Rogerson, David Romer, Rob Shimer, Carl Van Horn, Thomas Winberry, and Justin Wolfers for helpful comments, and Reid Stevens and Rebecca Sachs for providing excellent research assistance. The authors are solely responsible for the views expressed and any errors. Alan Krueger served as chairman of the Council of Economic Advisers (2011-13) and as assistant secretary and chief economist at the U.S. Department of the Treasury (2009-10), where he worked on policies and analysis related to unemployment. Judd Cramer served as staff economist (2011-12) and visiting economist (2013-14) and David Cho served as staff economist (2011-12) and economist (2012-13) at the Council of Economic Advisers, where they also worked on policies and analysis related to unemployment. 


\section{References}

Abowd, John M., and Arnold Zellner. 1985. "Estimating Gross Labor-Force Flows." Journal of Business \& Economic Statistics 3, no. 3: 254-83.

Abraham, Katharine, and Robert Shimer. 2002. "Changes in Unemployment Duration and Labor Force Attachment." In The Roaring Nineties, edited by Alan Krueger and Robert Solow. New York: Russell Sage Foundation.

Ball, Laurence, and Sandeep Mazumder. 2011. "The Evolution of Inflation Dynamics and the Great Recession.” Brookings Papers on Economic Activity, Spring: 337-81.

Barnichon, Regis, and Andrew Figura. 2013. "Declining Labor Force Attachment and Downward Trends in Unemployment and Participation." Working Paper no. 2013-88, Finance and Economics Discussion Series. Washington: Board of Governors of the Federal Reserve System.

Bernanke, Ben. 2007. "Inflation Expectations and Inflation Forecasting." Remarks delivered at the National Bureau of Economic Research Summer Institute, Cambridge, Mass., July 10.

.2010. "The Economic Outlook and Monetary Policy." Speech delivered at the Federal Reserve Bank of Kansas City Economic Symposium, Jackson Hole, Wyo., August 27.

Blanchard, Olivier Jean, and Peter Diamond. 1989. "The Beveridge Curve." Brookings Papers on Economic Activity, no. 1: 1-76.

—. 1994. "Ranking, Unemployment Duration, and Wages." Review of Economic Studies 61, no. 3: 417-34.

Blanchard, Olivier Jean, and Lawrence H. Summers. 1987. "Hysteresis in Unemployment." European Economic Review 31, no. 1: 288-95.

Chan, Sewin, and Ann Huff Stevens. 2001. "Job Loss and Employment Patterns of Older Workers." Journal of Labor Economics 19, no. 2: 484-521.

Chetty, Raj. 2008. "Moral Hazard vs. Liquidity and Optimal Unemployment Insurance." Journal of Political Economy 116, no. 2: 173-234.

Davis, Steven, and Till von Wachter. 2011. "Recessions and the Costs of Job Loss." Brookings Papers on Economic Activity, Fall: 1-72.

DeLong, J. Bradford, and Lawrence H. Summers. 2012. "Fiscal Policy in a Depressed Economy." Brookings Papers on Economic Activity, Spring: 233-97.

Elsby, Michael W. L., Bart Hobijn, Ayşegül Şahin, and Robert G. Valletta. 2011. "The Labor Market in the Great Recession-An Update to September 2011." Brookings Papers on Economic Activity, Fall: 353-84.

2013. "On the Importance of the Participation Margin for Labor Market Fluctuations.” Working Paper no. 2013-05. San Francisco: Federal Reserve Bank of San Francisco.

Elsby, Michael W. L., Ryan Michaels, and Gary Solon. 2009. "The Ins and Outs of Cyclical Unemployment." American Economic Journal: Macroeconomics no. 1: 84-110.

Farber, Henry S., and Robert G. Valletta. 2013. "Do Extended Unemployment Benefits Lengthen Unemployment Spells? Evidence from Recent Cycles in the US 
Labor Market.” Working Paper no. 19048. Cambridge, Mass.: National Bureau of Economic Research.

Fujita, Shigeru, and Giuseppe Moscarini. 2013. "Recall and Unemployment." Working Paper no. 19640. Cambridge, Mass.: National Bureau of Economic Research.

Ghayad, Rand. 2013. "The Jobless Trap." Working Paper (http://media.wix.com/ ugd/576e9a_f6cf3b6661e44621ad26547112f66691.pdf).

Ghayad, Rand, and William Dickens. 2012. "What Can We Learn by Disaggregating the Unemployment-Vacancy Relationship?" Public Policy Brief no. 12-3. Boston: Federal Reserve Bank of Boston.

Gordon, Robert. 2013. "The Phillips Curve Is Alive and Well: Inflation and the NAIRU during the Slow Recovery." Working Paper no. 19390. Cambridge, Mass.: National Bureau of Economic Research.

Hall, Robert E., and Sam Schulhofer-Wohl. 2013. "Measuring Matching Efficiency with Heterogeneous Jobseekers.” Mimeo. Stanford University.

Heckman, James, and Burton Singer. 1984. "A Method for Minimizing the Impact of Distributional Assumptions in Econometric Models for Duration Data." Econometrica 52, no. 2: 271-320.

Hobijn, Bart, and Ayşegül Şahin. 2012. "Beveridge Curve Shifts across Countries since the Great Recession." Paper presented at the International Monetary Fund's 13th Jacques Polak Annual Research Conference, Washington, D.C., November 8-9.

Hotchkiss, Julie, M., Melinda Pitts, and Fernando Rios-Avila. 2012. "A Closer Look at Nonparticipants during and after the Great Recession." Working Paper no. 2012-10. Atlanta: Federal Reserve Bank of Atlanta.

Katz, Lawrence F. 1986. "Layoffs, Recall, and the Duration of Unemployment." Working Paper no. 1825. Cambridge, Mass.: National Bureau of Economic Research.

Katz, Lawrence F., and Alan B. Krueger. 1999. "The High-Pressure U.S. Labor Market of the 1990s." Brookings Papers on Economic Activity 30, no. 1: 1-65.

Katz, Lawrence F., and Bruce D. Meyer. 1990. "Unemployment Insurance, Recall Expectations, and Unemployment Outcomes." Quarterly Journal of Economics 105, no. 4: 973-1002.

Kiefer, Nicholas M. 1988. "Economic Duration Data and Hazard Functions." Journal of Economic Literature 26, no. 2: 646-79.

Kroft, Kory, Fabian Lange, Matthew J. Notowidigdo, and Lawrence F. Katz. 2014. "Long-Term Unemployment and the Great Recession: The Role of Composition, Duration Dependence, and Non-Participation.” Working Paper no. 20273. Cambridge, Mass.: National Bureau of Economic Research.

Krueger, Alan B., and Andreas Mueller. 2011. "Job Search, Emotional WellBeing, and Job Finding in a Period of Mass Unemployment: Evidence from High-Frequency Longitudinal Data." Brookings Papers on Economic Activity, Spring: 1-57.

Krusell, Per, Toshihiko Mukoyama, Richard Rogerson, and Ayşegül Şahin. 2011. "A Three-State Model of Worker Flows in General Equilibrium." Journal of Economic Theory 146, no. 3: 1107-133. 
Mortensen, Dale T., and Christopher A. Pissarides. 1994. "Job Creation and Job Destruction in the Theory of Unemployment." Review of Economic Studies 61, no. 3: 397-415.

Mueller, Andreas. 2012. "Separations, Sorting and Cyclical Unemployment.” IZA Discussion Paper no. 6849, Institute for the Study of Labor, Bonn.

Mueller, Andreas, Jesse Rothstein, Till von Wachter. 2013. "Unemployment Insurance and Disability Insurance in the Great Recession." Working Paper no. 19672. Cambridge, Mass.: National Bureau of Economic Research.

Nekarda, Christopher J. 2009. “A Longitudinal Analysis of the Current Population Survey: Assessing the Cyclical Bias of Geographic Mobility." Working Paper (http://chrisnekarda.com/papers/geographic-mobility.pdf) (with data updated through December 2013).

Okun, Arthur M. 1973. "Upward Mobility in a High-Pressure Economy.” Brookings Papers on Economic Activity 1: 207-52.

Polivka, Anne E., and Stephen M. Miller. 1994. "The CPS after the Redesign: Refocusing the Economic Lens.” CRIW Labor Statistics Measurement Issues Conference.

Poterba, James M. and Lawrence H. Summers. 1986. "Reporting Errors and Labor Market Dynamics.” EconometricaSociety 54(6): 1319-1338.

Rothstein, Jesse. 2011. "Unemployment Insurance and Job Search in the Great Recession." Working Paper no. 17534. Cambridge, Mass.: National Bureau of Economic Research.

Shimer, Robert. 2012. "Reassessing the Ins and Outs of Unemployment." Review of Economic Dynamics 15, no. 2: 127-48.

- 2005. "The Cyclical Behavior of Equilibrium Unemployment and Vacancies." American Economic Review 95, no. 1: 25-49.

Stevens, Ann Huff. 1997. "Persistent Effects of Job Displacement: The Importance of Multiple Job Losses.” Journal of Labor Economics 15, no. 1: 165-88.

Stock, James H. 2011. "Discussion of Ball and Mazumder." Brookings Papers on Economic Activity (Spring): 387-402.

U.S. Council of Economic Advisers. 2014. Economic Report of the President. Washington, D.C.: U.S. Government Printing Office.

Valletta, Robert G. 2011. "Rising Unemployment Duration in the United States: Composition or Behavior?" Mimeo. San Francisco: Federal Reserve Bank of San Francisco.

Wanberg, Connie R., Jing Zhu, Ruth Kanfer, and Zhen Zhang. 2012. "After the Pink Slip: Applying Dynamic Motivation Frameworks to the Job Search Experience." Academy of Management Journal 55: 261-264.

Watson, Mark W. 2014. "Inflation Persistence, the NAIRU, and the Great Recession." Working Paper, Princeton University, January (and forthcoming in American Economic Review).

Zukin, Cliff, Carl E. Van Horn, and Charley Stone. 2011. "Categorizing the Unemployed by the Impact of the Recession." Working Paper. New Brunswick, N.J.: John J. Heldrich Center for Workforce Development. 


\section{Comments and Discussion}

\section{COMMENT BY}

KATHARINE G. ABRAHAM One of the most troubling features of the Great Recession has been the dramatic increase in long-term unemployment. As Alan Krueger, Judd Cramer, and David Cho note in this paper, the share of the unemployed who have been out of work 6 months or more averaged more than 40 percent in 2010, 2011, and 2012. Even as late as the middle of 2014, those out of work 6 months or more represented fully a third of all unemployed persons. As the economy continues to recover from the impact of the recession, whether and how the long-term unemployed can be reintegrated into the labor market has become a major concern.

Krueger, Cramer, and Cho are decidedly pessimistic about the prospects for getting the long-term unemployed back to work. While acknowledging that both the short-term and the long-term unemployed have faced significant labor market challenges, in their paper they focus primarily on those who have experienced an extended spell of unemployment. They document the low month-to-month job finding rates of the long-term unemployed as well as their low chances of finding employment even over somewhat longer time horizons. They attribute these difficulties to a combination of skill erosion and discouragement on the part of the long-term unemployed, together with discrimination against them on the part of employers. Further, the authors' analysis of how job-finding rates for the long-term unemployed have varied over time and across states leads them to conclude that an improvement in aggregate labor market conditions, by itself, will do little to help the long-term unemployed. If correct, this is an important and disturbing conclusion. I will come back to the question of whether we should believe it.

I would like to begin, however, with a few comments concerning some of the descriptive evidence on the job-finding experiences of unemployed 
Table 1. Subsequent Labor Market Status of the Short- and Long-Term Unemployed, 2008-12a

\begin{tabular}{lcc}
\hline Labor market status measure & $\begin{array}{c}\text { Short-term } \\
\text { unemployed } \\
\text { (<26 weeks) }\end{array}$ & $\begin{array}{c}\text { Long-term } \\
\text { unemployed } \\
\text { (27-plus weeks) }\end{array}$ \\
\hline Status one month after first observed & & \\
$\quad$ Employed & 22.9 & 10.7 \\
$\quad$ Unemployed & 56.7 & 68.3 \\
$\quad$ Not in the labor force & 20.4 & 20.9 \\
Status 15 months after first observed & 49.5 & 35.9 \\
$\quad$ Employed & 23.3 & 30.4 \\
$\quad$ Unemployed & 27.2 & 33.7 \\
$\quad$ Not in the labor force & & \\
Among those employed 15 months after first observed, & & 30.2 \\
$\quad$ status over 4 months ending in 15th month & 29.1 & 37.6 \\
$\quad$ Employed full-time in all months & 39.4 & 32.3 \\
$\quad$ Employed in all months, but part-time 1 or more & & \\
$\quad$ months & 31.5 & \\
$\quad$ Unemployed/out of labor force at least 1 month & & \\
\hline
\end{tabular}

a. Month-to-month transition estimates in first three rows of table calculated from BLS gross flows data. Remaining estimates from figure 7 of the paper in this volume by Alan Krueger, Judd Cramer, and David Cho.

workers presented in the paper. Much of this evidence consists of tabulations of Current Population Survey (CPS) data. Households selected for the CPS are interviewed for 4 months, taken out of the sample for 8 months, and then interviewed again for another 4 months; this rotation pattern permits the construction of short panels for those individuals selected into the survey sample. The authors show that, from 2008 through 2012, just 36 percent of the long-term unemployed were working 15 months after first being interviewed in the CPS and, more troubling, only 11 percent held full-time jobs that had lasted at least 4 months. They also examine data from the Survey of Income and Program Participation (SIPP) and the Work Trends Survey (WTS), which yield qualitatively similar conclusions.

What I find even more surprising than the results pertaining to the longterm unemployed, however, are the employment outcomes that the paper documents for the short-term unemployed. The gross flows data published by the Bureau of Labor Statistics displayed in figure 3 of the paper show a strong inverse relationship between the length of time a person has already been unemployed and the chance that he or she is employed the following month. Estimates based on the same gross flows data in the first row of my table 1 show that, over the period from 2008 through 2012, 
monthly job finding rates were more than twice as high, on average, for those unemployed 26 weeks or less as for those unemployed 27 weeks or more ( 23 percent versus 11 percent). Even taking into account that some of the observed transitions may be spurious, looking at the monthly numbers, one might have expected to see dramatic differences between the shortterm and long-term unemployed in their chances of being employed 12 to 15 months later. Over the same period from 2008 through 2012, however, just 50 percent of the short-term unemployed had a job 15 months after first being interviewed in the CPS, compared to 36 percent of the longterm unemployed. This difference is notable but much smaller than I might have anticipated. In addition, conditional on being employed 15 months later, the short-term unemployed were no more likely than the long-term unemployed to hold a stable, full-time job. The chances of finding a job, especially a stable job, during the recession and early recovery have been low for all unemployed workers, not just for the long-term unemployed.

In the story told by the authors, the poorer employment prospects of the long-term unemployed are caused by an extended period of unemployment having made these individuals less employable, rather than resulting from their having been less employable to start with (and thus more likely to have ended up as long-term unemployed). As the paper acknowledges, there is no consensus in the literature on the relative importance of these two factors-commonly referred to as state dependence versus heterogeneity-in explaining the lower job finding rate of the long-term unemployed. I find it hard to believe, however, that heterogeneity among the unemployed is not a part of the story. Further, it would be surprising if the relative employability of those in the pool of long-term unemployed did not vary with labor market conditions. In a very tight labor market, I would expect a large share of those who end up being unable to find work for many months to be essentially unemployable, but I would by no means expect the same to be the case during and in the aftermath of a deep recession.

In an effort to understand how changes in the characteristics of the unemployed over the course of the recession might have affected their jobfinding prospects, the authors model the relationship between the observable characteristics of unemployed people and their job finding rates. Using data for the years 2004 through 2006, they relate the probability of finding a job in the following month to the unemployed individual's education, experience (presumably defined as age minus years of education minus 5 or 6), industry, occupation, race, new entrant status, gender, and marital status. (The inclusion of industry and occupation in this model could 
be questioned, given that the association of these characteristics with job-finding success rates likely has varied over time, but I will not pursue that point here.) The model coefficients are used together with individuals' observable characteristics to construct job-finding probability estimates for both the short-term and the long-term unemployed over the period from 1994 through 2013. As can be seen in figure 4 of the paper, the average value of these projected probabilities varies little for either the short-term unemployed or the long-term unemployed, though during recessions the mix of characteristics among the long-term unemployed seems to change in ways that should make them slightly more employable. The authors interpret these results as suggesting that "any effect of changing worker heterogeneity on the pattern of job finding rates over the business cycle for the long-term unemployed is very small."

Even after controlling for the somewhat limited set of characteristics that can be observed in CPS data, however, there is likely to be significant residual variation in employability among the unemployed that is related to characteristics that are not observed (such as prior actual work histories, ability, and motivation). Further, I am skeptical that variation over time in the underlying employability of the long-term unemployed attributable to these unobserved factors can be safely ignored. In the authors' preferred specifications for the aggregate time series models reported in table 2 of the paper, the job-finding rate for the short-term unemployed appears to rise when unemployment falls, but the job-finding rate for the long-term unemployed does not. This is taken as evidence that tighter labor markets do not help the long-term unemployed. While I would not want to place too much weight on this sort of simple regression in any case, the seeming unresponsiveness of job-finding success rates among the long-term unemployed to the tightness of the labor market could be due to changes in the mix of unobserved employability characteristics among the long-term unemployed. As labor market conditions improve, the most attractive candidates among the long-term unemployed should tend to be the first ones hired. This should lead to a worsening in the average underlying employability of the remaining long-term unemployed, a change that could mask any beneficial effects of labor market tightening on the job-finding rate. For similar reasons, comparisons of the job-finding success rates of the long-term unemployed in low-unemployment states to the rates in high-unemployment states could be affected by differences in the average underlying employability of the long-term unemployed.

This is not the only reason to question the authors' pessimistic interpretation of the cross-state evidence. For their cross-state analysis, the authors 
assign each state to one of two categories based on whether the state's 2013 unemployment rate was above or below its average unemployment rate from 1982 through 2007. The paper makes much of the fact that, as shown in the top panel of their figure 16, job-finding rates in the states with belowaverage unemployment have risen for the short-term unemployed but remained low for the long-term unemployed. Because labor market conditions remained relatively weak through 2013 even for the states labeled as having below-average unemployment, however, it would be a mistake to conclude too much from this finding.

There are 11 states in the below-average unemployment category defined by Krueger, Cramer, and Cho: Alaska, Iowa, Louisiana, Montana, North Dakota, Oklahoma, Texas, Utah, Vermont, West Virginia, and Wyoming. This list includes just one large state (Texas, which according to the Bureau of Labor Statistics has a labor force of more than 12 million people) and several very small states (Alaska, Montana, North Dakota, Vermont, and Wyoming, all with labor forces of about half a million people or fewer, and West Virginia, with a labor force of less than a million people). The remaining 39 states and the District of Columbia are assigned to the aboveaverage unemployment category. The authors were kind enough to provide me with time series on the annual unemployment rates calculated for the two groups of states for the period from 1982 through 2013, weighted to reflect the size of each state's labor force. This is equivalent to treating each group of states as a pseudo-region and calculating unemployment rates for the two pseudo-regions.

The resulting estimates are displayed in my figure 1. Even among the 11 states in the group categorized as having below-average unemployment in 2013, the unemployment rate remained at 5.9 percent, well above the average rate prevailing in the same states in the decade prior to the start of the recession. The 2013 unemployment rate for this group of states can be considered below average only relative to a much longer period that includes the 1980s and early 1990s, when unemployment was much higher. It is not clear to me that this is a very meaningful comparison.

A possible point of confusion here is that, in the paper, the authors cite an average 2013 unemployment rate of just 5.2 percent for the states with below-average unemployment. That rate, however, is a simple average across the 11 states, with very small but low unemployment states (for example, North Dakota, which according to the Bureau of Labor Statistics had a labor force of about 400,000 and an unemployment rate of 2.9 percent in 2013) counting the same as the one big state with notably higher unemployment (Texas, with a labor force in excess of 12 million 
Figure 1. Unemployment Rates in States Categorized by Krueger, Cramer, and Cho as Having Below-Average versus Above-Average Unemployment in 2013, 1982-2013a

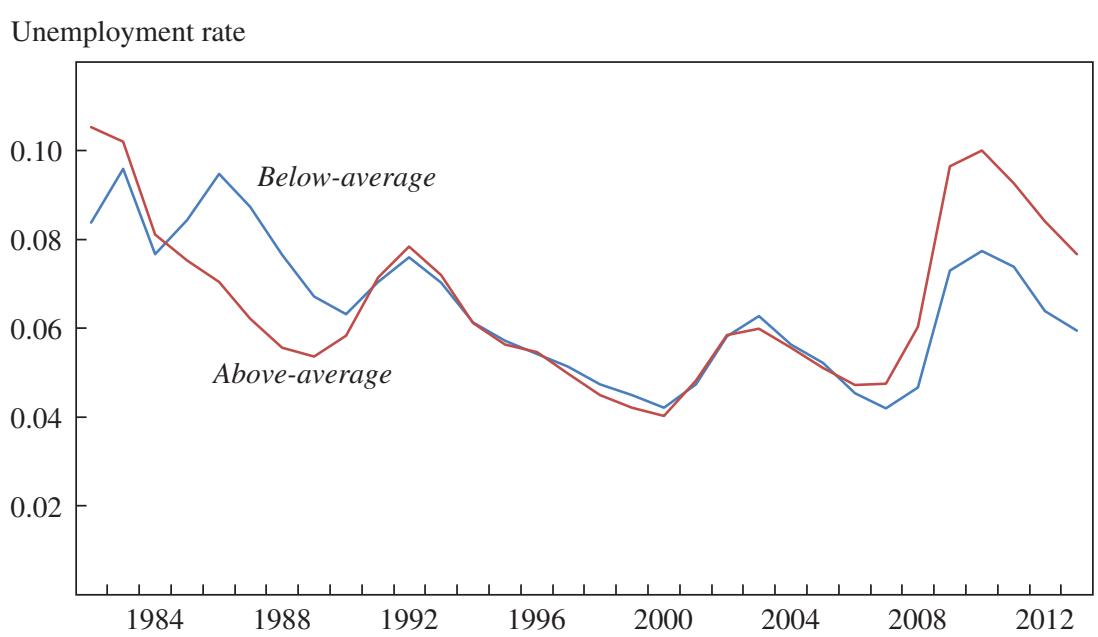

a. States are defined as having above-average or below-average unemployment in 2013 based on whether their 2013 unemployment rate exceeded or fell short of the average for that state over the period 1982 through 2007. The unemployment rates for states in each group are weighted by state labor force size to produce the group average. Estimates kindly provided by Alan Krueger, Judd Cramer, and David Cho.

and an unemployment rate of 6.3 percent in 2013). The weighted unemployment rates plotted in my figure 1 are more directly comparable to the weighted labor force transition rates displayed in the paper's figure 16 and provide a better indication of the labor market situation faced by the typical person in these states over time. An unemployment rate of 5.9 percent - the weighted average 2013 rate for the states with belowaverage unemployment-is high enough that I do not think anyone would expect any potential benefits of a tight labor market for the long-term unemployed to have been fully realized. In my judgment, the evidence presented in the paper does not provide a convincing rebuttal to the view that a stronger labor market should be expected to help the long-term unemployed.

Although Krueger, Cramer, and Cho look at several different data sets in the paper in a commendable effort to evaluate the robustness of their findings, a limitation common to all of these data sets is the lack of information about what the unemployed were doing before they entered that status. As already suggested, knowing more about the employability of the unemployed population and how this has varied over time and across states 
could help to inform our understanding of how likely these individuals are to eventually return to work.

Information from unemployment insurance wage records for those who later become unemployed could help to fill this gap. For example, wage record data could allow a researcher to examine whether and to what extent those who ended up as long-term unemployed during the Great Recession were more likely to have a prior history of stable employment than those recorded as long-term unemployed during the mid-2000s. Wage record data also could be helpful for developing a better understanding of the path that unemployed workers take back into employment. For example, it would be of interest to know whether and how the first jobs taken by the shortterm unemployed differ from the first jobs taken by the long-term unemployed. If the short-term unemployed were more likely to take short-lived jobs paying substantially less than their previous jobs, as one possibility, that might suggest a greater willingness to accept stopgap employment and offer a partial explanation for their higher job finding rate. Together with co-authors John Haltiwanger, Kristin Sandusky, and James Spletzer, I have recently begun work using the Census Bureau's Longitudinal EmployerHousehold Dynamics database, which allows us to link CPS respondents to their unemployment insurance wage records in order to examine these and related questions.

The extent to which a strong labor market can be expected to benefit the long-term unemployed has potentially important policy implications. If a tight labor market can successfully draw those who are currently long-term unemployed back into work, the case for the Federal Reserve Board to maintain a relatively accommodative monetary policy stance is bolstered. On the other hand, if tighter labor markets on their own will do little to help the long-term unemployed, the case for moving more quickly toward a tighter monetary policy stance may be strengthened. In either case, one might argue as the authors do for targeted policies to help the long-term unemployed. The paper does not provide any details about what such policies might look like. Based on past experience, designing and implementing effective individual-level interventions for this population is likely to be both difficult and costly.

\section{COMMENT BY}

ROBERT SHIMER This paper by Alan Krueger, Judd Cramer, and David Cho provides a careful and thorough documentation of the plight of the long-term unemployed in the United States. Through a series of figures 
and tables built on multiple data sources, the authors convincingly show that a worker who has been out of work for more than 6 months is unlikely to be working a year later and even less likely to have a stable job. In an average year since 1982, the average long-term unemployed worker has had a 14 percent chance of returning to stable full-time work one year later. The authors also show that the plight of the short-term unemployed is only slightly less bleak, with about a 17 percent chance of returning to stable full-time work (see figure 10 in the paper). In part, this small difference between the two groups of unemployed workers may reflect the fact that the long-term unemployed do not look very different from the shortterm unemployed, at least based on their observable characteristics (see figures 4 and 6 in the paper).

The results in this paper present an important series of snapshots of labor market transitions. Since the relevant data were first published, refined, and analyzed (Bureau of Labor Statistics 1982; Abowd and Zellner 1985; Poterba and Summers 1986; Blanchard and Diamond 1990), economists have measured the gross flow of workers between employment $(E)$, unemployment $(U)$, and out-of-the-labor-force $(O)$ using matched files from consecutive months of the Current Population Survey. The implicit assumption in virtually all of these papers is that a worker's employment status follows a (possibly time-varying) three-state Markov process. If in month $t$ a worker is in employment state $s_{t} \in\{E, U, O\}$, then the probability that he is in state $s_{t+1} \in\{E, U, O\}$ in month $t+1$ is given by some $\lambda_{s_{t}, s_{t+1}}(t)$. Moreover, the probability that he is in state $s_{t+2}$ in month $t+2$ is simply given by compounding these probabilities,

$$
\sum_{s_{t+1}} \lambda_{s_{t}, s_{t+1}}(t) \lambda_{s_{t+1}, s_{t+2}}(t+1) .
$$

This statistical model does not admit the possibility of duration dependence beyond that captured by the worker's current employment status. A worker who has been out of work for a year is as likely to find a job tomorrow as a newly unemployed worker.

Thinking about the gross flow of workers as a Markov process is consistent with most theoretical search-and-matching models. For example, Dale Mortensen and Christopher Pissarides (1994) emphasize the endogenous and time-varying rate at which unemployed workers become employed and employed workers become unemployed, but the paper assumes that all unemployed workers are equally likely to find a job and all employed workers are equally likely to lose their job at any point in 
time. ${ }^{1}$ Much of my own theoretical work is even simpler, focusing only on the determination of the probability of finding a job, assumed to be common across all workers at any moment in time. ${ }^{2}$

But the gross flow of workers is not a first-order Markov process. Indeed, many economists have long recognized that the probability of finding a job depends on the duration of job search (Lancaster 1979; Nickell 1979). A large literature seeks to understand whether this is because of some structural duration dependence, whereby any given unemployed worker becomes less likely to find a job the longer he stays unemployed, or because of preexisting heterogeneity, whereby those workers who have a higher probability of finding a job are decreasingly observed at long unemployment durations because they have already found a job. ${ }^{3}$ But the literature on gross worker flows has mostly steered clear of those debates by focusing on the average probability that an unemployed worker finds a job or drops out of the labor force. The results in the present paper should cause any future analyst of worker flows to apologize before he imposes the assumption that all unemployed workers are the same.

ANOTHER LOOK AT DURATION DEPENDENCE. At the risk of redundancy, I will state the evidence for duration dependence in a slightly different way than the authors do. My table 1 shows my calculations ${ }^{4}$ of the

1. In fact, in a version of the Mortensen and Pissarides (1994) model with aggregate shocks, workers who have had a job for a longer duration are more likely than other workers to lose their job at the instant that an adverse aggregate shock hits, so there is positive duration dependence in the job-loss probability.

2. For example, see Shimer (2005).

3. In the paper under discussion, coauthors Krueger, Cramer, and Cho state that "the hypothesis we seek to test is that the longer workers are unemployed the less they become tied to the job market"; however, the authors only consider the role of observed worker characteristics. Once one allows for the possibility that some heterogeneity may be uncorrelated with observed worker characteristics and hence unobserved, decomposing these two factors requires either appropriate variation in observable characteristics (Elbers and Ridder 1982; Heckman and Singer 1984) or observations on multiple unemployment spells (Honoré 1993; Alvarez, Borovičková, and Shimer 2014). The paper under discussion argues that, because observed heterogeneity does not account for too much of overall duration dependence, unobserved heterogeneity is also likely to be unimportant. There is no theoretical or empirical justification for this claim, although of course it may be correct.

4. See Shimer (2012) for details on my methodology, which is broadly similar to the approach in the present paper. Note that the numbers I give here do not correct for time aggregation bias. 
Table 1. Mean Transition Rates between Employment, Unemployment, and Out-of-the-Labor-Force, May 1967-December 2013

\begin{tabular}{llccc}
\hline & & \multicolumn{3}{c}{ Month $\mathrm{t}$} \\
\cline { 3 - 5 } & & Employment & Unemployment & $\begin{array}{c}\text { Out-of-the- } \\
\text { labor-force }\end{array}$ \\
\hline month $t+1$ & Employment & 0.955 & 0.262 & 0.046 \\
& Unemployment & 0.014 & 0.510 & 0.025 \\
& Out-of-labor-force & 0.031 & 0.228 & 0.929 \\
\hline
\end{tabular}

average transition rates between employment, unemployment, and outof-the-labor-force between May 1967 and December 2013. For example, 95.5 percent of workers employed in one month were still employed, and 1.4 percent of them were unemployed, in the next month. The ergodic distribution of this transition matrix implies that about 59.2 percent of individuals on average are employed, 3.6 percent are unemployed, and the remaining 37.2 percent are out-of-the-labor force in the long run. ${ }^{5}$

The transition matrix in table 1 tells us that 51.0 percent of workers who were unemployed in one month were also unemployed in the following month, a much higher probability than for the average person. But under the assumption that employment status follows a first-order Markov process, the matrix implies that the probability of being unemployed one year later would be only 3.7 percent, virtually the same as the population average of 3.6 percent. Thus the Markov model denies the possibility that unemployment is a very persistent state, something that the present paper forcefully tells us is incorrect. Similarly, the Markov model implies that the probability that an employed worker is employed one year later is 70.9 percent, when in reality this number exceeds 90 percent according to my calculations from the Current Population Survey. ${ }^{6}$

These calculations affect how we view the costs of unemployment. According to the Markov assumption, and according to simple search

5. Because attrition from the Current Population Survey is not random, these numbers differ from the published population shares- 60.3 percent employed, 4.0 percent unemployed, and 35.6 percent out-of-the-labor-force-but they are close enough for my purposes here.

6. One caveat with all these calculations is attrition from the Current Population Survey. While attrition is relatively small between consecutive months, I can match only 60 to 75 percent of eligible individuals between consecutive years. This problem may limit the usefulness of the Current Population Survey for addressing long-run transition rate issues and seems to be an issue in the present paper as well. Still, the robustness of the paper's main conclusions to the use of alternative data sources is reassuring. 
models like that of Mortensen and Pissarides (1994) and Shimer (2005), unemployment is a transitory problem, with workers quickly returning to employment and thereafter appearing to be just like other employed workers. But the present paper reminds us that some unemployment episodes are extremely persistent. This is true for multiple reasons: because of observed and unobserved heterogeneity, because of structural duration dependence in the exit rate from unemployment, and because newly employed workers are likely to return to unemployment, cycling through many short-term jobs before returning to stable long-term employment. ${ }^{7}$

The Markovian assumption affects more than just employment status. We also know that when an employed worker loses a stable job, the impact on his income persists 20 years later, long after the employment consequences have evaporated (Ruhm 1991; Jacobson, LaLonde, and Sullivan 1993; Davis and von Wachter 2011). Workers can easily save to smooth their consumption in the face of short, transitory unemployment spells, but it is not easy to self-insure against persistent and repeated spells of unemployment.

One way to deal with this issue is through brute force: add more states to the transition matrix. This is basically the approach taken by this paper. The authors compute the probability of employment in 4 consecutive months next year conditional on the duration of an unemployment spell this year and on many other statistics in this vein. While this approach offers some fascinating results, it has a shortcoming: it is unclear how to usefully summarize and make sense of all the results in the paper, as well the thousands of similar results that the authors could compute but do not report.

TWO ALTERNATIVE MODELS. I want to use the bulk of my discussion to propose and sketch two alternative, theoretically motivated, and feasible modeling approaches. The first is a hidden-state Markov model and the second views unemployment duration as an optimal stopping time. Both of these approaches give a structure that can be estimated with the right data set, both offer insight into the nature of long-term unemployment, and both help us think more generally about the non-Markovian nature of employment as well as unemployment. Workers who have been employed for a long time are also much more likely to stay employed than are newly employed workers.

According to the hidden-state Markov model, all workers transition between $N$ possible hidden states, switching from state $i$ to state $j$ with

7. On the latter possibility, see Hall (1995). 
probability $\mu_{i j}$ in any month. We cannot observe a worker's state, however. Instead, if a worker is in state $i \in\{1, \ldots, N\}$, we measure her as being employed with probability $\varphi_{i E}$, unemployed with probability $\varphi_{i U}$, and outof-the-labor-force with probability $\varphi_{i 0}$. The measurement probabilities are independent and identically distributed over time conditional on the worker's state, but they may be unconditionally serially correlated because the state is serially correlated.

The hidden-state Markov model addresses two of the key issues in CPS data. The first is classification error. Early research by John Abowd and Arnold Zellner (1985) and by James Poterba and Lawrence Summers (1986) used reinterview surveys to demonstrate the prevalence of this problem. Particularly egregious was the misclassification of unemployed workers as out-ofthe-labor-force and vice versa. This misclassification generated numerous spurious transitions between those two states. Unfortunately, no comparable reinterview survey has been conducted more recently, and since the CPS instrument has changed substantially over time, the relevance of that older research may be limited.

The hidden-state Markov model directly admits the possibility of classification error by allowing a worker's measured employment status to change even if her hidden state remains unchanged. One can think of this as formalizing a procedure proposed by Michael Elsby, Bart Hobijn, and Ayşegül Şahin (2013), replacing transitions from unemployment to outof-the-labor-force and back to unemployment with a sequence of 3 months of unchanged activity, should that interpretation be warranted by the data. This would show up in the hidden-state Markov model as a persistent state that is sometimes measured as unemployed and sometimes measured as out-of-the-labor-force.

The second key issue addressed by the hidden-state Markov model is the one at the heart of the present paper: structural duration dependence. The model allows, for example, for two states in which workers are always measured as unemployed, $\varphi_{i U}=\varphi_{j U}=1$, but with different probabilities of exiting for an employed state, $\mu_{i k} \neq \mu_{j k}$. One state would capture a worker trapped in persistent unemployment while the other would capture a more transitory experience.

The type of data in the present paper is exactly what is needed to estimate the hidden-state Markov model. Suppose we fix the number of unobserved states $N$; this could later be determined through some optimality criterion. We then must estimate $N \times(N-1)$ transition rates and $2 \times N$ measurement probabilities. ${ }^{8}$ We observe each worker's employment status in the Current Population Survey for up to 8 months, giving a total of $2 \times 3^{7}=4,374$ pos- 
sible transition rates. Using these data, we can estimate the Markov transition matrix and measurement equation using maximum likelihood.

More generally, we might fix the measurement equation as constant across months and allow the transition rate matrix to vary over time. This would allow us to study how the evolution of the unemployment rate (for example) reflects the evolution of workers across states. These estimates could then be given economically meaningful names, such as "strongly attached to employment" or "persistently unemployed." More importantly, the estimates could be used to forecast future unemployment rates given current estimates of the distribution of workers across the hidden states. In some sense, this exercise would be similar to the present paper's calibration model in section VII, but would not require the modeler to pre-specify the relevant states. While implementing this procedure goes beyond the scope of my discussion, the evidence in the present paper highlights the importance of this research program.

The second modeling approach views unemployment and employment duration as the outcome of optimal stopping problems. In reduced form, a worker is described by some continuous-state variable $\omega(t)$ that follows a persistent stochastic process. If she is employed, she keeps working as long as $\omega(t)>\underline{\omega}$, while if she is unemployed she starts working as soon as $\omega(t)>\bar{\omega}$ for some thresholds $\bar{\omega} \geq \underline{\omega}$. The stochastic process for $\omega$ and the thresholds $\underline{\omega}$ and $\bar{\omega}$ give rise to a statistical model of employment and unemployment durations.

This model has flexible underpinnings. For example, $\omega(t)$ may represent a worker's wage minus any unemployment income and value from leisure. The worker chooses to work whenever the wage sufficiently exceeds the alternative use of her time and stops working when the difference falls too low. The distance between the thresholds represents a fixed cost that the worker must pay to take a job. This is a model of voluntary unemployment.

Alternatively, $\omega(t)$ may represent the difference between a worker's timevarying marginal revenue product and constant wage. A monopsonist is willing to pay the cost of hiring the worker whenever her productivity is sufficiently high relative to her wage and fires the worker when her productivity falls too low. Depending on the level of the wage, the worker may

8. The rows of $N^{2}$ Markov matrix sum to 1 , so there are only $N \times(N-1)$ free parameters there. Likewise, there are three possible measurements for each of the $N$ states, again giving $2 \times N$ free parameters. 
wish she could work more often than she does, in which case the wage rigidity induces involuntary unemployment. These two interpretations of the model have the same reduced-form representation in terms of the stochastic process for $\omega(t)$ and the endogenous thresholds $\bar{\omega}>\underline{\omega}$, but of course their normative implications are very different.

This second model can generate persistent spells of employment and unemployment to the extent that $\omega$ is persistent. All unemployment spells, for example, start with $\omega$ equal to the lower barrier $\underline{\omega}$ and end the next time that $\omega$ hits the upper barrier $\bar{\omega}$. Moreover, even if $\omega$ is constant or increasing on average, selection may induce it to fall within the sample of continuously unemployed workers, driving those workers further and further from the threshold of working.

Fernando Alvarez and Shimer (2011) and Shimer (2008) explore the theoretical and empirical implications of this type of model for the behavior of unemployment duration and wage dynamics. In current research, Alvarez, Katarína Borovičková, and Shimer (2014, unpublished) are exploring the empirical content of this type of model in more detail. In that current research, we place a particular restriction on $\omega(t)$, namely that it follows a random walk with drift, but we allow the parameters of the random walk, as well as the thresholds $\underline{\omega}$ and $\bar{\omega}$, to differ arbitrarily across workers. We find that the model has testable implications and is identified if we have data on the duration of two or more unemployment spells per worker. We then test the model and estimate it using social security data from Austria.

Our preliminary results indicate that the model predicts a substantial amount of structural duration dependence, even though we also estimate that there is a substantial amount of heterogeneity across Austrian workers. For example, consider the mean amount of time that a worker in Austria spends between full-time jobs. For a worker who just left her job, this averages about 42 weeks, with a standard deviation of 28 weeks across workers. After one year, the mean remaining duration of a jobless spell conditional on not having found a job has increased to 149 weeks, that is, by nearly 2 years. About 20 percent of the increase is accounted for by changes in the composition of the workers who remain out of work, while the remainder is structural, an increase in residual nonemployment duration for the same worker.

The present paper points to another potential use of the stopping-time model. In the future it may be possible to use a model like this, together with historical observed transitions between employment and unemployment, to deduce the distribution of the latent-state variable $\omega$ across work- 
ers at a point in time. This would be invaluable in forecasting the future evolution of employment and unemployment, a task for which our current models are inadequate.

Both the hidden-state Markov model and the optimal stopping-time model can explain the key facts outlined in this paper. A worker who has been out of work for longer is less likely to find a job. When she does find one, as a newly employed worker she is likely to lose the job and return to unemployment. The future employment prospect of any unemployed worker is poor, and increasingly so for workers who have been unemployed for longer.

In closing, I want to comment briefly on the policy implications coming out of this analysis. There are none. The observations in the present paper do not tell us whether hysteresis is a market failure, that is, whether there is any violation of the first welfare theorem. And if hysteresis is a market failure, the observations do not tell us whether realistic public policies can mitigate that failure. What this paper does tell us is that economists need answers to these important questions.

\section{REFERENCES FOR THE SHIMER COMMENT}

Abowd, John, and Arnold Zellner. 1985. "Estimating Gross Labor-Force Flows." Journal of Business and Economic Statistics 3, no. 3: 254-83.

Alvarez, Fernando, Katarína Borovičková, and Robert Shimer. 2014. "Decomposing Duration Dependence in the Job Finding Rate in a Stopping Time Model." Unpublished manuscript, University of Chicago.

Alvarez, Fernando, and Robert Shimer. 2011. "Search and Rest Unemployment." Econometrica 79, no. 1: 75-122.

Blanchard, Olivier, and Peter Diamond. 1990. "The Cyclical Behavior of the Gross Flows of U.S. Workers." Brookings Papers on Economic Activity 2: 85-143.

Bureau of Labor Statistics. 1982. Gross Flow Data from the Current Population Survey, 1970-80. Washington. (Currently available from http://catalog.hathitrust. org/Record/009633170).

Davis, Steven J., and Till von Wachter. 2011. "Recessions and the Costs of Job Loss." Brookings Papers on Economic Activity 43, no. 2: 1-72.

Elbers, Chris, and Geert Ridder. 1982. "True and Spurious Duration Dependence: The Identifiability of the Proportional Hazard Model." Review of Economic Studies 49, no. 3: 403-09.

Elsby, Michael W. L., Bart Hobijn, and Ayşegül Şahin. 2013. "On the Importance of the Participation Margin for Labor Market Fluctuations." Working Paper no. 2013-05, Federal Reserve Bank of San Francisco.

Hall, Robert E. 1995. "Lost Jobs." Brookings Papers on Economic Activity 1: 221-56. 
Heckman, James J., and B. Singer. 1984. “A Method for Minimizing the Impact of Distributional Assumptions in Econometric Models for Duration Data." Econometrica 52, no. 2: 271-320.

Honoré, Bo E. 1993. "Identification Results for Duration Models with Multiple Spells." Review of Economic Studies 60, no. 1: 241-46.

Jacobson, Louis S., Robert J. LaLonde, and Daniel G. Sullivan. 1993. "Earnings Losses of Displaced Workers.” American Economic Review 83, no. 4: 685-709.

Lancaster, Tony. 1979. "Econometric Methods for the Duration of Unemployment." Econometrica 47, no. 4: 939-56.

Mortensen, Dale, and Christopher Pissarides. 1994. "Job Creation and Job Destruction in the Theory of Unemployment." Review of Economic Studies 61, no. 3: 397-415.

Nickell, Stephen J. 1979. "Estimating the Probability of Leaving Unemployment." Econometrica 47, no. 5: 1249-66.

Poterba, James, and Lawrence Summers. 1986. "Reporting Errors and Labor Market Dynamics.” Econometrica 54, no. 6: 1319-38.

Ruhm, Christopher J. 1991. "Are Workers Permanently Scarred by Job Displacements?" American Economic Review 81, no. 1: 319-24.

Shimer, Robert. 2005. "The Cyclical Behavior of Equilibrium Unemployment and Vacancies." American Economic Review 95, no. 1: 25-49.

- 2008. "The Probability of Finding a Job." American Economic Review 98, no. 2: $268-73$.

2012. "Reassessing the Ins and Outs of Unemployment." Review of Economic Dynamics 15, no. 2: 127-48.

GENERAL DISCUSSION Robert Hall opened the discussion by offering his interpretation of the Beveridge curve and its actual significance. He felt the traditional view of the Beveridge curve confused dynamics with labor market matching efficiency, the curve being thought to loop back to its starting position because of the dynamics of the business cycle. The actual mechanism, he said, was the efficiency of the labor market matching function, and he therefore suggested demoting or eliminating the Beveridge curve.

Hall also suggested that the heterogeneity in the duration of unemployment could be explained by differentiating those individuals who lost their jobs permanently from those who did not. Citing work by Sam Schulhofer-Wohl and himself, Till von Wachter, and Steve Davis, he said that permanent job losers exit unemployment much less frequently than others. The mix of the unemployed shifted toward permanent job losses, which explains much of the Beveridge curve dynamics.

Gary Burtless agreed with Hall regarding the importance of the causes of job loss for the unemployed. He added that permanent job losers are different from voluntary job losers in that they qualify for unemployment 
insurance. He pointed to the paper's finding that the decline in the share of people exiting unemployment status to leave the labor force after long durations is partly accounted for by unemployment insurance extensions, which typically occur at that stage of a recession. Burtless noted that in the most recent recession, unemployment insurance eligibility was increased by 73 weeks of benefits instead of the usual 10 to 20 weeks. One effect of this has been to make unemployment a stickier state than it has been in previous recessions.

Jonathan Pingle thought the paper had ambiguous implications, at best, for monetary policy. If the long-term unemployed eventually exit the labor force, then the Beveridge curve would return to the relationship that existed when the Fed thought that NAIRU was 5 percent. But Pingle also thought the authors were suggesting that a stronger economic recovery could help reemploy the long-term unemployed, preventing them from permanently leaving the work force, which would also help return the Beveridge curve to its precrisis relationship. He then wondered what the authors considered to be the appropriate monetary policy.

Caroline Hoxby found herself convinced by the paper that the long-term unemployed are indeed on the margins of the labor market. It seemed to her that the long-term unemployed are "lemons," in the sense that they are unlikely to rejoin the labor force. How they become that way matters. It could be because their skills no longer fit the needs of the modern labor force or because the state of being unemployed itself has scarred their skills, and each of these two causes would have different policy implications. If the labor market has changed in a way that has caused their skills to lose relevance, then the long-term unemployed should be moved out of the labor force in order to get the labor market functioning again. But if their skills deteriorated due to the condition of their unemployment, then they should never have been allowed to become unemployed to begin with.

Valerie Ramey expressed surprise that the long-term unemployment rates in low-unemployment states were so similar to those in high-unemployment states. She interpreted the existence of so many long-term unemployed in such economically diverse places as evidence that some national policy, and not weak labor markets, was the cause.

David Romer noted that the short-term unemployed also seem to look as if they are on the margins of the labor force. He related this to Ramey's point regarding the cross-state variation in exit rates. Even in low-unemployment states, Romer found himself surprised by how slowly the short-term unemployed were exiting unemployment. He expressed interest in knowing whether the employed also look like they are marginally attached to the 
labor force. For example, after a year, how many of the employed population still have full-time employment?

Donald Kohn wondered about the effect of nominal wage rigidity, particularly in the context of the nonlinearities in the Phillips curve that George Akerlof, William Dickens, and George Perry noted several years earlier. ${ }^{1}$ These nonlinearities occur because employers are reluctant to lower nominal wages. Kohn thought that the wage rigidities would be particularly harmful for the long-term unemployed. According to his thinking, nominal wage rigidities should have made this recession worse than previous recessions, and he was surprised that the recession was not actually worse.

Peter Orszag noted that the decline in the job openings data reported in the Job Openings and Labor Turnover series was not materially larger than during previous recessions. This recession was different, in that although the job openings rate had begun to rise again in accordance with previous recession recoveries, the job hiring rate had not increased.

Alan Krueger responded to the commenters first by suggesting that, when looking at transition rates over a long period of time, one finds that the distinction between the short-term and long-term unemployed is less meaningful than it might seem, because in the most recent recession many of the short-term unemployed became long-term unemployed. The rate of transition from being unemployed to being out-of-the-labor-force is also very cyclical, he noted, and that pattern of cyclicality explains a large portion of the dynamics of the Beveridge curve. He suggested that a composition effect might be responsible for some of the cyclicality, but observed characteristics only account for about one-fifth of the movements in labor force withdrawal of the long-term unemployed. During a recession, Krueger said, groups of people with strong attachment to the labor force might be more likely to get laid off than during normal conditions, but in their research he and his coauthors had controlled for the observables of the unemployed. This implied to him that the cyclical effect was largely due to state-dependency. $\mathrm{He}$ also agreed with discussant Katharine Abraham that the long-term unemployed showed a surprisingly strong attachment to the labor force during the recession and shortly afterward, and he suggested that it now looks like the attachment is regressing to its mean.

Krueger acknowledged that two parts of the paper were inconsistent. In one part, the authors assumed that once an unemployed worker gets a job he or she looks like other employed people, while in another they find that

1. The paper referred to is "Near-Rational Wage and Price Setting and the Optimal Rates of Inflation and Unemployment," Brookings Papers on Economic Activity, 2000:1. 
the long-term unemployed tend to get transitory jobs when they do get jobs. He agreed that this dependency should be modeled explicitly. (Turning to his coauthor, doctoral student Judd Cramer, he also suggested, tongue in cheek, that he do the modeling as a research project.) Responding to Hall's comments, Krueger agreed that there has been a shift in the matching function, although he added that the matching function from 2002 to 2007 still explained about 80 percent of the rise in unemployment and the loop around the Beveridge curve. Matching efficiency could explain the missing 20 percent. Responding to Orszag's similar point, he said the differences in matching efficiency between the long-term and short-term unemployed could account for the lower hiring rate.

Regarding Hoxby's point about workers becoming lemons, Krueger said that he interpreted the evidence as supporting a state-dependency story. $\mathrm{He}$ noted that many individuals' behavior changed significantly over the spell of unemployment (for example, they search less intensively for a job), and their family characteristics and mental health changed as well (for example, divorce and depression rise). Lastly, he thought that unemployment insurance was effective at keeping people in the labor force through the search requirement and possibly raised the prospect of their eventually finding a job as a result. 
